\title{
LAS ÁREAS MARINAS PROTEGIDAS EN ESPAÑA: UNA VISIÓN DE CONJUNTO
}

\section{THE MARINE PROTECTED AREAS IN SPAIN: A GENERAL OVERVIEW}

\author{
ASENSIO NAVARRO ORTEGA \\ Departamento de Derecho Administrativo \\ Universidad de Granada \\ asenavort@ugr.es
}

Fecha de recepción: 14 de octubre de 2019 / Fecha de aceptación: 2 de diciembre de 2019

RESUMEN: El legislador español define las Áreas Marinas Protegidas (AMPs) como espacios naturales designados para la protección de ecosistemas, comunidades o elementos biológicos o geológicos del medio marino, incluidas las áreas intermareal y submareal que, en razón de su rareza, fragilidad, importancia o singularidad, merecen una protección especial. La naturaleza jurídica de estos espacios es compleja y diversa. Sobre las mismas se proyecta una variedad de instrumentos y mecanismos de protección que requieren de un análisis dirigido a establecer formas racionales para mejorar su operatividad, seguimiento y control. El presente trabajo pretende profundizar en el desarrollo de esta figura de protección que, desde su incorporación al ordenamiento español en 2007, a través la Ley de Patrimonio Natural y de la Biodiversidad, pone en conexión el régimen jurídico ambiental de estos espacios con las políticas sectoriales ambientales que se proyectan en el mismo espacio físico. En un contexto global de cambio climático y degradación ambiental, la gestión de las AMPs debe fundarse en la combinación de criterios ecológicos y socioeconómicos que garanticen modelos de sostenibilidad, alcanzando un reconocimiento amplio a nivel nacional e internacional.

RESUM: El legislador espanyol defineix les àrees marines protegides (AMP) com a espais naturals designats per a la protecció d'ecosistemes, comunitats 0 elements biològics o geològics del medi marí, incloses les àrees intermareal $\mathrm{i}$ submareal, que mereixen una protecció especial per la seva raresa, fragilitat, importància o singularitat. La naturalesa jurídica d'aquests espais és complexa i 
diversa. Sobre les AMP es projecta una varietat d'instruments i mecanismes de protecció que requereixen una anàlisi dirigida a establir formes racionals per millorar-ne l'operativitat, el seguiment i el control. Aquest treball pretén aprofundir en el desenvolupament d'aquesta figura de protecció, que des que es va incorporar a l'ordenament espanyol el 2007, a través la Llei de patrimoni natural i de la biodiversitat, posa en connexió el règim jurídic ambiental d'aquests espais amb les polítiques sectorials ambientals que es projecten al mateix espai físic. En un context global de canvi climàtic i degradació ambiental, la gestió de les AMP s'ha de fonamentar en la combinació de criteris ecològics i socioeconòmics que garanteixin models de sostenibilitat, per tal d'aconseguir un reconeixement ampli a escala nacional i internacional.

ABSTRACT: The Spanish legislator defines Marine Protected Areas (MPAs) as natural spaces designated for the protection of ecosystems, communities, biological or geological elements of the marine environment, including intertidal and subtidal areas that, due to their singularity, fragility or importance, they deserve special protection. The legal framework of MPAs is complex and diverse. A variety of regulations and mechanisms are projected on them, which require an analysis aimed to establish rational ways to improve their monitoring and control processes. This paper intends to deepen at development of Marine Protection Areas since its incorporation into the Spanish legislation in 2007 through the Natural Heritage and Biodiversity Law; this law connects the environmental legal regime of these spaces with other sectorial policies and environmental projects that are linked to the same area. In a global context of climate change and environmental degradation, the management of MPAs should be based on the combination of ecological and socio-economic criteria in order to guarantee sustainability models, reaching a wider recognition at national and international levels.

Palabras clave: Áreas marinas protegidas - Derecho ambiental - Usos ecológicos - Planificación - Continuidad ecológica - Biodiversidad - cambio climático.

Paraules clau: Àrees marines protegides - dret ambiental - usos ecològics planificació - continuïtat ecològica - biodiversitat - canvi climàtic. 
Keywords: Marine protected areas - Environmental Law - Ecological uses Conservation - Planning - Ecological continuity - Biodiversity - Climate change.

Sumario: I.-ESTADO DEL ARTE: LOS ESPACIOS MARINOS Y SU PROTECCIÓN EN EL ORDENAMIENTO ESPAÑOL II.-LA PROTECCIÓN DE LOS ESPACIOS NATURALES MARINOS EN SU CONTEXTO PLANETARIO: EL DON DE PROTEGER PARA SER PROTEGIDOS III.- ALCANCE Y SIGNIFICADO DE LOS ESPACIOS MARINOS PROTEGIDOS: BREVES APUNTES DE DERECHO COMPARADO IV.-LA REGULACIÓN DE LAS ÁREAS MARINAS PROTEGIDAS EN ESPAÑA: BASES PARA UNA PROTECCIÓN JURÍDICA INTEGRADA. 4.1. Estructura competencial superpuesta. 4.2. La Ley 42/2007, de Patrimonio Natural y de la Biodiversidad como origen y marco general para la protección de las áreas marinas protegidas stricto sensu en España. 4.3. Las AMPs y el conocimiento científico aplicado y los instrumentos de inventarización. 4.4. La Ley 33/2015, de 21 de septiembre, por la que se modifica la LNPB: la sustancial referencias a la conectividad ecológica. 4.5. La Ley 41/2010, de Protección del medio marino, como esquema de integración de objetivos: a) Los fundamentos ambientales de la Ley: las estrategias marinas y los criterios técnico-jurídicos del programa de medidas; b) La Red de Áreas Marinas Protegidas (RAMPE); c) El plan integral de protección de áreas marinas protegidas. V. LA INTEGRACIÓN DE LAS AREAS MARINAS PROTEGIDAS EN OTROS INSTRUMENTOS DE PLANIFICACIÓN AMBIENTAL Y SECTORIAL. 5.1. Las AMPs en el ámbito de gestión de la política marítima integrada. 5.2. Las AMPs en las políticas de Gestión Integrada de Zonas Costeras y de protección y uso sostenible del litoral. 5.3. Las AMPs en el contexto de las políticas de gestión integrada del agua: la protección ambiental de las aguas costeras y de transición. 5.4. Las AMPs y su vinculación material con otras regulaciones sectoriales. 5.5. El carácter singular de las áreas marinas protegidas en España. VI. CONCLUSIONES. VII. BIBLIOGRAFÍA

\section{ESTADO DEL ARTE: LOS ESPACIOS MARINOS Y SU PROTECCIÓN EN EL ORDENAMIENTO ESPAÑOL ${ }^{1}$}

Diferentes textos internacionales insisten en una idea: el medio marino (es decir, los océanos, todos los mares y las zonas costeras adyacentes) constituye un todo integrado que es esencial para el sistema mundial de sustentación de la vida y un valioso recurso que ofrece posibilidades ilimitadas para el desarrollo sostenible ${ }^{2}$. Este fundamental axioma exige a la Administración pública intervenir en la gestión de los espacios marinos protegidos, asegurando su conservación.

\footnotetext{
${ }^{1}$ Vid. Ricard, P.: "Les aires marines protégées en haute mer et la difficile conciliation entre droit de la mer et droit de l'environnment", en Chaumette, P. (Coord.): Transforming the ocean law by requirement of the marine environment conservation, Marcial Pons, Madrid, 2019, pp. 249-269.

${ }^{2}$ Capítulo 17 de la Agenda 21 del Programa de Naciones Unidas para desarrollar la sostenibilidad a nivel mundial, siendo aprobada por 173 gobiernos en la Conferencia de las NN.UU. sobre Medio Ambiente y Desarrollo, celebrada en Río de Janeiro en 1992. Abarca aspectos económicos, sociales y culturales, así como relativos a la protección del Medio Ambiente.
} 
Las Áreas Marinas Protegidas ${ }^{3}$, a las que se dirige este estudio, desempeñan un papel crucial en la consecución de una estrategia eficiente de gestión del medio marino en España. La figura del área marina protegida (en adelante, AMP ó AMPs), fue introducida en España por la Ley 42/2007, de 13 de diciembre, del patrimonio natural y de la biodiversidad (en adelante, LPNB). Las AMPs constituyen una categoría de espacios naturales protegidos, según disponen los art. 30 y 33 LPNB, para la protección de ecosistemas, comunidades o elementos biológicos o geológicos del medio marino que, en razón de su rareza, fragilidad, importancia o singularidad, merecen una protección especial.

La naturaleza jurídica de las AMPs es compleja y diversa. Sobre su espacio se proyecta una gran variedad de instrumentos y mecanismos de protección que requieren de un análisis dirigido a establecer formas racionales para mejorar su operatividad, seguimiento y control.

Las AMPs se configuran como una categoría individualmente considerada y a la vez como un género común que engloba a otras figuras de protección. Serán AMPs stricto sensu los Espacios Naturales protegidos cuando su objeto sea la protección de un espacio mixto (marítimo-terrestre) o exclusivamente marino, conforme a lo establecido en el art. 33 LPNB.

Los muchos instrumentos de regulación y planificación espacial marina a nivel internacional albergan figuras de protección que podrán ser consideradas AMPs en un sentido amplio; encontramos, entre otros, el Convenio para la protección de los humedales de Importancia Internacional (Convenio de Ramsar); la lista de Patrimonio Mundial configurada por la UNESCO; las áreas protegidas del Convenio para la protección del medio marino del Atlántico Nordeste (OSPAR); las zonas especialmente protegidas de importancia para el Mediterráneo (ZEPIM) del Convenio de Barcelona; las Reservas de la Biosfera, también de la UNESCO; y el Convenio de Naciones Unidas sobre el Derecho del Mar de 1982 $(\mathrm{UNCLOS})^{4}$.

\footnotetext{
${ }^{3}$ Sobre las áreas marinas protegidas como concepto, vid. Ortíz García, M.: La conservación de la biodiversidad marina: las áreas marinas protegidas, Comares, Granada, 2002; y, La gestión eficiente de la zona costera. Los parques marinos, Tirant lo Blanch, Valencia, 2003.

${ }^{4}$ Otras normas de carácter supraestatal que se relacionan con este espacio son: Convenios de mares regionales: - Convenio de Barcelona $(1976,1995)$ para la protección del medio marino y de la región costera del Mediterráneo; - Protocolo sobre las Zonas Especialmente Protegidas
} 
Los espacios marinos clasificados conforme a algunas de las categorías jurídicas de espacios naturales protegidos previstas en los arts. 30 y ss. LPNB (Parques, Monumentos y Paisajes protegidos, Reservas, Zonas de Especial Conservación, Lugares de interés comunitario, ZEPIM, Reserva de la biosfera, Áreas OSPAR, etc.) también podrán ser AMPs, pero adoptarán el régimen jurídico expresamente previsto para cada una de ellas.

Por tanto, la superposición de figuras de protección en la orla litoral y las áreas de transición tierra-mar no se limita a lo establecido en los acuerdos internacionales; a nivel nacional y autonómico también existe una multiplicidad de instrumentos, de donde se extrae la importancia que tiene que las Administraciones públicas faciliten la información necesaria para llevar a cabo la gestión actualizada de estos espacios.

El art. 29.2 LPBN establece que, si se solapan en un mismo lugar distintas figuras de espacios protegidos, "las normas reguladoras de los mismos, así como los mecanismos de planificación deberán ser coordinados para unificarse en un único documento integrado, al objeto de que los diferentes regímenes aplicables en función de cada categoría conformen un todo coherente". El mismo precepto señala que "constituyen una excepción a lo anterior los supuestos en que las distintas figuras de espacios protegidos correspondan a diferentes Administraciones públicas, sin perjuicio de la colaboración interadministrativa pertinente". Este mandato, como comentaremos, no resulta sencillo ni pacífico de aplicar al proyectarse sobre un ámbito normativo y de gestión multinivel que engloba a diferentes sectores de ordenación, administraciones y objetivos.

Dada esta enumeración amplia de figuras de protección que se incluyen, la figura del AMP, en sentido amplio, puede se un concepto controvertido por resultar

\footnotetext{
y la Diversidad Biológica en el Mediterráneo (1995): - Convenio de París (OSPAR, 1992) para la protección del medio ambiente marino del Atlántico Nordeste: - Anexo V sobre la protección y conservación de los ecosistemas y de la diversidad biológica de las áreas marítimas (1998); el Convenio de Bonn (1979) sobre la conservación de las especies migratorias de fauna silvestre: - Acuerdo de Mónaco sobre la conservación de cetáceos del Mar Negro; en la zona del Mar Mediterráneo y Zona Atlántica Contigua (ACCOBAMS, 1996); - Acuerdo de Canberra para la conservación de albatros y petreles (ACAP, 2002); el Convenio de Río de Janeiro (1992) sobre la Diversidad Biológica:- Mandato de Yakarta sobre biodiversidad marina y costera (1995); la Red Global de Áreas Marinas Protegidas para el año 2012, establecida por la Cumbre Mundial sobre Desarrollo Sostenible, celebrada en Johannesburgo (2002), en el marco del Convenio sobre la Diversidad Biológica.
} 
poco definida, como se discutió en el momento de su creación ${ }^{5}$. En todo caso, su declaración y posterior gestión representa un desafío para la Administraciones, dada la interdependencia natural y la continuidad ecológica de estos espacios.

Desde que se aprobara el Real Decreto 1629/2011, de 14 de noviembre, por el que se declara como AMP y como Zona Especial de Conservación el espacio marino de "El Cachucho" (un hito al ser la primera AMP exclusivamente marina declarada) se ha avanzado en el diseño y desarrollo de políticas sectoriales que toman como referencia el espacio marino. El retraso de la intervención pública necesaria a estos efectos ${ }^{6}$, sin embargo, responde a planteamientos que tienen que ver con la tardanza y el carácter propositivo que todavía alcanzan muchas medidas, así como la superposición de figuras heterogéneas que vincula a los mismos. Estas áreas, cuando son protegidas por instrumentos internacionales, cumplirán el régimen jurídico que se establezca en dichos convenios y acuerdos internacionales, sin perjuicio de que se puedan aplicar regímenes de protección más específicos cuando la ordenación y gestión coincida parcial o totalmente con dichas áreas delimitadas, siempre que así se recoja en las citadas normas internacionales (ex art. 50 LPNB).

En general, existe una política de ampliación y reconocimiento de AMPs y una mayor concienciación institucional y social en España por proteger; pero no está claro el esquema de integración normativa y competencial que se debe seguir (en cuanto a la primacía de obligaciones y objetivos que imponen unos instrumentos normativos $\mathrm{u}$ otros). El mar y la franja costera adyacente concentran la mayor proporción de usos y de actividades antrópicas (industriales, extractivas, comerciales, turísticas, urbanísticas, recreativas, pesqueras...). Al utilizar como soporte un espacio físico compartido, los poderes públicos deben velar por su conservación desde una perspectiva multidisciplinar

\footnotetext{
5 "No tanto porque el artículo que la introduce no sea claro sino porque lo más normal es que en el mundo real no se trate de una categoría específica de espacio natural protegido sino una categoría genérica para agrupar, por la especialidad que supone el medio marino, otras categorías cuando se establecen en el mar" (...) "parece confuso crear una categoría que lo más normal es que sea otra cosa acogida a otra categoría". Vid. Consejo de Estado, Dictamen 913/2007, de 17 de mayo.

${ }^{6}$ Vid. Giménez Casalduero, M.: "Las áreas marinas protegidas: nuevas perspectivas a la luz de la ley 42/2007, del patrimonio natural y de la biodiversidad", en Revista catalana de Dret ambiental, Vol. I, núm. 1, 2010, pp. 1-31.
} 
e integrada que posibilite la adaptación de las políticas públicas a los objetivos de desarrollo sostenible.

\section{LA PROTECCIÓN DE LOS ESPACIOS NATURALES MARINOS EN SU CONTEXTO PLANETARIO: EL DON DE PROTEGER PARA SER PROTEGIDOS}

La declaración y protección de áreas marinas protegidas conlleva un impacto mensurable en la generación de economías de escala, en la rentabilidad y productividad de los costes asociados a un no deterioro ambiental de las mismas. La "salud oceánica", como se ha dado en llamar, exige una intervención administrativa eficiente para contraprogramar los datos, alarmantes, que se vienen conociendo relacionados con el impacto que provocarán los efectos del cambio climático ${ }^{7}$. Por otro lado, el ritmo extractivo, muy intensivo, de los recursos oceánicos, está conduciendo a un agotamiento de sus ecosistemas y de los modelos productivos asociados a ellos.

Los mares y océanos representan el $99 \%$ del espacio vital disponible de nuestro planeta, cubren un $71 \%$ de la superficie de la Tierra y contienen un $90 \%$ de la biosfera; albergan más diversidad biológica que los ecosistemas terrestres y de agua dulce juntos. No es exagerado afirmar, por tanto, que son espacios imprescindibles para la conservación de la vida y un factor de desarrollo esencial para la prosperidad económica y el bienestar social, que se enfrenta a importantes desafíos jurídicos ${ }^{8}$.

\footnotetext{
${ }^{7}$ Se estima que, desde 1985, han desaparecido la mitad de los arrecifes de coral que existen en el mundo. Solo en el año 2016, un tramo de más de $600 \mathrm{kms}$ de la Gran barrera de arrecifes se vio gravemente dañado debido a un proceso de decoloración. De las 600 poblaciones o subpoblaciones de peces vigiladas por los organismos de investigación internacionales, el 31\% alcanzan niveles de captura insostenibles; y el 58\% de los caladeros está agotados. Las poblaciones de peces se redujeron un 49\% entre 1970 y 2012.Vid. PNUMA: Fronteras 2017. Nuevos temas de interés ambiental, Programa de las Naciones Unidas para el Medio Ambiente, Nairobi (Kenia), 2017.

${ }^{8}$ En los últimos años una serie de obras se adentran en esta materia, entre las que cabe citar: Zambonino Pulito, M.: La protección jurídico-administrativa del medio marino: tutela ambiental y transporte marítimo, Valencia, Tirant lo Blanch, Madrid, 2001; Sanz Larruga, F. J. (Dir.): Estudios sobre la ordenación, planificación y gestión del litoral: hacia un modelo integrado y sostenible, Observatorio del Litoral de la Universidad de A Coruña, 2009; Lacleta Muñoz, J. M. et al: El régimen jurídico de los espacios marinos en el derecho español e internacional, Madrid, Colegio de Ingenieros de Caminos, Canales y Puertos, 2009; Barreira López, A. (Dir.): Gobernanza para la protección del medio marino en España: Guía Práctica, Instituto Internacional de Derecho y Medio Ambiente (IIDMA), Madrid, 2009; Núñez Lozano, M. C. (Dir.): Hacia una política marítima integrada de la Unión Europea: estudios de política marítima, Madrid, lustel, 2010; Parejo
} 
Se calcula que el impacto económico de los océanos asciende, como mínimo, a 24 billones de dólares ${ }^{9}$. Si los océanos fueran un país, serían la séptima economía del mundo. Como hipótesis que acompaña a este razonamiento, se sostiene que una red de zonas marinas protegidas que abarque entre el $10 \mathrm{y}$ el 30 por ciento de los océanos tendría un coste de gestión de entre 45.000 y 228.000 millones de dólares; pero podría generar beneficios sociales y económicos del orden de 622.000 millones y 1.145 billones de dólares en el período base comprendido entre 2015 y 2050, siendo superiores en una proporción de 3 a 20 veces a los costes que conllevaría su protección ${ }^{10}$; y, ello, sin tener suficientemente en cuenta las economías de escala y los efectos acumulativos que tienen estas mediciones y que no se representan adecuadamente en los datos.

Existe un consenso científico generalizado en señalar que habría que proteger al menos, el 10 por ciento de las zonas litorales y marinas (es una de las metas de Aichi para la diversidad biológica, y constituye un objetivo de la Agenda 2030 para el desarrollo sostenible). En los últimos 15 años, la superficie declarada ha ido en aumento hasta alcanzar el 25 por ciento del total declarado, pero resulta todavía muy insuficiente a efectos de lo que se había previsto alcanzar para el año $2020^{11}$.

Según los datos del Centro Mundial de Vigilancia de la Conservación (CMVC) del programa de Naciones Unidas para el medio ambiente (PNUMA), hasta 2010, los espacios protegidos cubrían el $12,7 \%$ de la superficie de la tierra (zona emergida); pero sólo el 1,6\% de los océanos; y, de este porcentaje, solo el $4 \%$ correspondía a los mares, dentro de la jurisdicción de cada Estado (0-200 millas náutica ${ }^{12}$.

\footnotetext{
Navajas, T.: La proyección de la ordenación física de usos sobre la costa y el mar próximo: la planificación del "Aquitorio", Madrid, lustel, 2011; y, Arana García, E. y Sanz Larruga, F.J. (Dirs.): La ordenación jurídica del medio marino en España, Civitas, Cizur Menor (Navarra), 2012.

${ }^{9}$ Vid. PNUMA: Fronteras 2017, op. cit., p. 37.

${ }^{10}$ Vid. Ibídem, pp. 37 y 42.

${ }^{11}$ El área marina protegida de la Gran Barrera de Coral australiana (the Great Barrier Reef) en el Mar del Coral, frente a la costa de Queensland; se extiende sobre unos 2,600 kilómetros de longitud, pudiendo ser distinguido incluso desde el espacio.

12 Vid. Gjerde, K.M.: "Challenges to protecting the marine environment beyond national jurisdiction", en Int. Journal Mar Coast Law, núm. 27, 2012, pp. 839 y ss.
} 
En términos cuantitativos se contabilizan 238.563 áreas protegidas a escala mundial que cubren 20 millones de $\mathrm{km} 2$, el equivalente a $14,9 \%$ de la superficie terrestre. En relación a la protección marina se habría alcanzado el 7\%, fundamentalmente en la zona exclusiva económica (hasta 200 millas náuticas, con un $16,8 \%$ y sólo un $1,2 \%$ más allá de 200 millas náuticas desde la costa $)^{13}$. La ausencia, en este sentido, de un marco internacional para el establecimiento de zonas marinas protegidas en las zonas que están fuera de la jurisdicción nacional, supone un importante freno ${ }^{14}$.

En julio de 2017 se habían designado 15.292 zonas marinas protegidas en el mundo que equivalen al 5,7 de la superficie de todos los océanos; el 14,4 por ciento de las zonas litorales y marinas se situaba bajo jurisdicción nacional. Las cifras, a pesar de ser positivas, son, también irreales: primero, porque no miden los estándares de eficacia ni la consecución de objetivos; en segundo lugar, porque la superficie agregada de 45 de estas 15.292 zonas marinas protegidas constituye el $72 \%$ de la superficie total protegida, lo que ilustra cuán focalizado se encuentra la designación de AMP en determinadas regiones específicas ${ }^{15}$.

De este lado, una protección excelsa de una determinada zona puede ser insuficiente en la medida en que los beneficios de su gestión son remotos si no se pueden extrapolar a otras regiones (principio de continuidad ecológica). Calidad y cantidad en la protección, por tanto, son dos ideas que deben tender a equilibrarse. Como ha señalado MARTíN MATEO, sólo las áreas marinas relativamente acotadas y sometidas a la jurisdicción de un Estado y organizadas según Acuerdos concretos de ámbito internacional, son susceptibles de una planificación relativamente eficaz e integrada ${ }^{16}$.

\footnotetext{
${ }^{13}$ AA.VV.: EUROPARC-España Anuario 2018 del estado de las áreas protegidas en España, Ed. Fundación Fernando González Bernáldez, Madrid, 2019, p. 13.

${ }^{14}$ Vid. Ariche, M.: "La gobernanza de la biodiversidad marina en las zonas fuera de la jurisdicción nacional: desafíos y perspectivas", en Revista de Estudios Jurídicos de la Univ. de Jaén, núm.16, 2016.

${ }^{15}$ Vid. PNUMA: Fronteras 2017, op. cit., p. 38.

16 Vid. Martín Mateo, R.: Planificación ambiental oceánica, disponible en http://huespedes.cica.es/gimadus/MARTINMATEO.html (octubre de 2019). El autor subraya la necesidad de que la gestión ambiental de los océanos, a través de la planificación ambiental oceánica, se base en la aplicación de una política reflexiva que tenga en cuenta los diversos usos del medio marino.
}

6) Vid. Barreira López, A. (Dir.): Gobernanza para... op. cit. pág. 12. 
Un ejemplo de esto que comentamos es el reciente informe del PNUMA Enabling effective and equitable marine protected áreas: guidance on combining governance approaches que, al analizar 34 casos de estudio en todo el mundo, concluye que solamente la mitad de las zonas marinas declaradas recibieron una calificación suficiente y, por tanto, una protección acorde con su condición de área protegida. La lógica de la protección camina de la mano con la necesidad de esbozar planteamientos realistas, en línea con las siguientes cuestiones: ¿es siempre beneficioso procurar una protección más esforzada de determinados espacios? ¿puede condicionar una protección de un ecosistema el logro de los objetivos ambientales perseguidos en otros ecosistemas? ¿cómo afecta la protección a ultranza de un espacio al desarrollo de otras políticas sectoriales? ¿se deben establecer formas de prelación estables para ordenar los conflictos competenciales entre actividades sectoriales e intensivas? ¿bajo qué criterios?

\section{ALCANCE $Y$ SIGNIFICADO DE LOS ESPACIOS MARINOS PROTEGIDOS: BREVES APUNTES DE DERECHO COMPARADO}

El término Área Marina Protegida, a nivel internacional, identifica la protección ambiental de un espacio marítimo sea cual sea el grado de defensa y conservación aplicado al mismo. Se emplea tanto para proteger el litoral, como en espacios oceánicos abiertos. Sus obligaciones se basan en niveles de regulación, protección y enfoques de gestión adaptativos.

La Unión Internacional de Conservación de la Naturaleza (UICN) ha definido el AMP como:

cualquier área intermareal o submareal terrestre, junto con el agua circundante, su flora y fauna asociada y sus características culturales, los cuales han sido preservados por ley u otro medio efectivo de protección de una parte o todo un medio ambiente" $" 17$.

Más recientemente, esta misma organización ha definido el AMP como un espacio geográfico claramente definido, reconocido, dedicado y gestionado, mediante medios legales $u$ otros tipos de medios eficaces, para conseguir la conservación a largo plazo de la naturaleza y de sus servicios ecosistémicos y

\footnotetext{
17 Vid. AA.VV.: UICN, Directrices para las categorías de Manejo de Áreas protegidas, Centro de Parques Nacionales y Áreas Protegidas (CPNAP) - Centro Mundial de Monitoreo de la Conservación (WCMC), Cambridge (Inglaterra), 1995,
} 
sus valores culturales asociados (Dudley, 2008). Por su parte, el Grupo Especial de Expertos Técnicos (GEET) sobre áreas protegidas marinas y costeras define a estas figuras como:

Toda zona dentro del medio marino o contigua al mismo, junto con las aguas que la cubren y la flora, la fauna y rasgos históricos y culturales asociados, que ha sido reservada por acto legislativo o por otros medios efectivos, incluso a través de la costumbre, para que su diversidad biológica y costera goce de un nivel de protección superior al de su entorno"18.

Para el Banco Mundial, toda AMP puede ser caracterizada por un gradiente de tamaño y de protección.

El origen de las AMPs como figura de protección lo encontramos en los "Marine sanctuaries", regulados por primera vez en la Marine Protection, Research and Sanctuaries Act de 1972, de los Estados Unidos de América ${ }^{19}$. A nivel internacional y europeo, la creación de las AMPs se introduce en el Convenio de Barcelona de 1976, denominado Convenio para la Protección del Medio Marino y de la Región Costera del Mediterráneo, tras las enmiendas realizadas en 1995, que introdujeron el Protocolo sobre las Zonas especialmente protegidas y la diversidad biológica en el Mediterráneo, en el año 1995, y que fue ratificado por España en $1999^{20}$.

Como explican SUÁREZ DE VIVERO y RODRÍGUEZ MATEOS, es posible distinguir dos modelos de planificación espacial marina. En primer lugar, un modelo "environmentoriented", más centrado en aspectos puramente ambientales -como los Marine Bioregional Plans y el Great Barrier Reef Marine Park Zoning Plan de Australia, el Florida Keys National Marine Sanctuary de EE UU, el Eastern Scotian Shelf Integrated Management Plan de Canadá. Y, en segundo lugar, el modelo de planificación "technical-energy-oriented", en el que

\footnotetext{
${ }^{18}$ Definición adoptada en la séptima Conferencia de las Partes $(\mathrm{CdP})$ del Convenio de Diversidad Biológica (Kuala Lumpur, febrero 2004), Decisión VII/5, párrafo 10.

${ }^{19}$ Sobre dicha figura se proyecta el National Marine Sanctuaries Program (NMSP), una división del National Oceanic and Atmospheric Administration (NOAA) que administra 14 áreas marinas protegidas con una superficie estimada de 2,030,000 km². Sobre esta cuestión, se puede consultar mi trabajo: "La gestión integrada del litoral en los Estados Unidos de América y su perspectiva comparada con el régimen jurídico español", en Revista de Administración Pública, núm. 185, 2011, pp. 365-397.

${ }^{20}$ Vid. Instrumento de Ratificación del Protocolo sobre las zonas especialmente protegidas y la diversidad biológica en el Mediterráneo y anexos, adoptado en Barcelona el 10 de junio de 1995 y en Montecarlo el 24 de noviembre de 1996, respectivamente. (BOE, núm 302, de 18 de diciembre de1999).
} 
la planificación espacial es la pieza clave para la coordinación entre usos marinos (algunos de ellos de fuerte implantación e impacto espacial); estos últimos sirven para superar el enfoque sectorial, para resolver conflictos entre usos y entre usuarios y para asignar áreas concretas a usos específicos, favoreciendo al mismo tiempo la consecución de importantes demandas sociales (desarrollo económico, I+D+i, sostenibilidad ambiental, abastecimiento energético) ${ }^{21}$.

Este doble esquema es, precisamente, el que se viene desarrollando desde el seno de las instituciones europeas, que tratan de regular estos espacios con un enfoque basado, por un lado, en la protección ambiental de los mismos; y, por el otro, en ordenar la gestión y racionalización de usos específicos en dicho espacio, tratando de establecer estructuras de cooperación y de sostenibilidad complementarias.

\section{LA REGULACIÓN DE LAS ÁREAS MARINAS PROTEGIDAS EN ESPAÑA: BASES PARA UNA PROTECCIÓN JURÍDICA INTEGRADA.}

La variedad de figuras para designar el territorio que ocupan las AMPs hace que sea difícil sistematizar los principios de gestión y exista una confusión inherente a las mismas en relación al reparto de competencias y del grado de vinculación a las políticas públicas que confluyen en ellas; pero, también, en cuanto a las estrategias y los usos zonificados que se regulan (con qué intensidad deben producirse, quién es la Administración responsable de tutelarlos...). Como ha señalado VALENCIA MARTÍN, la tutela del medio marino presenta muy distintas vertientes, máxime si se parte de una protección ambiental amplia comprensiva de la conservación de los recursos naturales; vertientes que van desde la prevención, reducción y control de las distintas formas de contaminación del mar hasta la protección de espacios marinos o de especies en peligro de extinción, pasando por la conservación de los recursos pesqueros, y que pueden merecer un tratamiento diferenciado desde la perspectiva competencial ${ }^{22}$.

\footnotetext{
${ }^{21}$ Vid. Suárez de Vivero, J.L. y Rodríguez Mateos, J.C.: "España en el contexto europeo (La Ley de protección del medio marino y la planificación espacial marina)", Revista Ambienta, núm. 94, Ministerio de Medio Ambiente y Medio Rural y Marino, 2011, p. 2, disponible en: http://www.revistaambienta.es/WebAmbienta/marm/Dinamicas/secciones/articulos/suarezvivero .htm (octubre de 2019).

22 Vid. Valencia Martín, G.: ¿De quién es el mar?: La distribución de competencias entre el estado
} 


\subsection{Estructura competencial superpuesta.}

La configuración jurídica de las áreas marinas protegidas resulta confusa por el alcance y determinación de las competencias territoriales que pueden asumir las Comunidades Autónomas en la protección del medio marino. Mientras el Estado ha desarrollado su competencia para establecer la legislación básica en la materia, la normativa autonómica ha tenido cada vez más en cuenta al medio marino como un espacio de continuidad ecológica el territorio terrestre que resultaría complementario a la ordenación del territorio ${ }^{23}$.

La LPNB señala, como regla general, que (art. 37. apdos. 1 y 2):

Corresponde a las comunidades autónomas la declaración y la determinación de la fórmula de gestión de los espacios naturales protegidos en su ámbito territorial". Sin embargo, "corresponde a la Administración General del Estado la declaración y la gestión de los Espacios Naturales Protegidos, excepto en los casos en que exista continuidad ecológica del ecosistema marino con el espacio natural terrestre objeto de protección, avalada por la mejor evidencia científica existente, en cuyo caso esas funciones corresponderán a las comunidades autónomas.

Las competencias autonómicas para gestionar las áreas marinas protegidas, al igual que en otros espacios naturales protegidos que se extienden al mar, es limitada y tiene alcance excepcional por ser el mar territorial un espacio reservado a la competencia del Estado. De esta forma, sólo en ocasiones extraordinarias, debidamente justificadas y acreditadas, puedan ejercitarse competencias autonómicas en dicho espacio por parte de las Comunidades Autónomas, como así reconoce una sólida jurisprudencia (SSTC 38/2002, de 14 de febrero, 8/2013, 87/2013 99/2013, de 23 abril, relativa a la declaración y gestión de parques nacionales marinos; y STS de 2 de julio $2008^{24}$, y de 10 de

\footnotetext{
y las comunidades autónomas en materia de protección del medio marino, en SOSA WAGNER (Coord.): El derecho administrativo en el umbral del siglo XXI: homenaje al profesor Dr. D. Ramón Martín Mateo, Tirant lo Blanch, 2000, p. 3590.

${ }^{23}$ Véase, por ejemplo, la Ley $5 / 2005$, de 26 de mayo, para la conservación de los espacios de relevancia ambiental de Baleares, dice que "son espacios naturales protegidos las zonas terrestres y marinas de les Illes Balears que sean declaradas como tales en la forma prevista en esta ley atendiendo a la representatividad, la singularidad, la fragilidad o el interés de sus elementos o sistemas naturales" (art. 10).

24 El Tribunal Supremo (rec. 4583/2004) declara la nulidad de varios artículos del Decreto 127/2001, por el que se declaró Parque Natural la Península de Llevant y las Reservas Naturales de Cap Farrutx y Cap de Freu, y del Plan de Ordenación de los Recursos Naturales de la Península de Llevant, por entender que dichos preceptos se proyectan sobre las aguas exteriores o mar territorial.
} 
mayo 201125). El criterio de territorialidad (competencia autonómica en la parte terrestre y competencia estatal en la marina, con matices) se puede modular cuando las características y circunstancias del espacio natural a proteger demanden una gestión unitaria.

Las competencias autonómicas en materia ambiental se extienden a las aguas interiores y a los islotes situados en las mismas, pero no alcanzan a las aguas exteriores (mar territorial) y a los islotes situados en las mismas, salvo circunstancias excepcionales ${ }^{26}$. Siguiendo los parámetros del art.36.1 de la LPNB, las CC.AA. han declarado espacios naturales protegidos (de acuerdo a la categorización recogida en su propia legislación) que se extienden al ámbito territorial y a las aguas marinas en los casos en que exista continuidad ecológica entre el espacio natural terrestre que debe ser objeto de protección

De este modo, la competencia en materia de AMPs se relaciona con las competencias que ostenta la Administración General del Estado para la protección de la biodiversidad marina ${ }^{27}$.El art. 6 de la LPNB señala que son competencias del Estado:

a) Cuando se trate de espacios, hábitat o áreas críticas situados en áreas marinas bajo soberanía o jurisdicción nacional, siempre que no concurran los requisitos del artículo 36.1 .

b) Cuando afecten, bien a especies cuyos hábitats se sitúen en los espacios a que se refiere el párrafo anterior, bien a especies marinas altamente migratorias.

c) Cuando, de conformidad con el derecho internacional, España tenga que gestionar espacios situados en los estrechos sometidos al Derecho internacional o en alta mar.

La declaración de una AMP es competencia estatal y se llevará a cabo a través de Real Decreto, tras la propuesta efectuada por el Ministerio competente

\footnotetext{
25 La Sentencia (rec. 2102/2007) resuelve el recurso de casación interpuesto por la Administración General del Estado contra la Sentencia de la Sala de lo ContenciosoAdministrativo del Tribunal Superior de Justicia de la Comunidad Valenciana, de 27 de diciembre de 2006, siendo partes recurridas la Generalitat Valenciana y el Ayuntamiento de Benidorm.

${ }^{26}$ Por ejemplo, en relación con el PORN de la Serra Gelada y de su zona litoral, que incluía tanto aguas interiores como exteriores.

${ }^{27}$ Según el artículo 2 del Convenio sobre la Diversidad Biológica, se entiende por "diversidad biológica" la variabilidad de organismos vivos de cualquier fuente, incluidos, entre otras cosas, los ecosistemas terrestres y marinos y otros ecosistemas acuáticos y los complejos ecológicos de los que forman parte; comprende la diversidad dentro de cada especie, entre las especies y de los ecosistemas.
} 
(actualmente, el Ministerio de Transición Ecológica), previo informe del Consejo Asesor de Medio Ambiente y la Conferencia Sectorial de Pesca ex art. 27.1 de la Ley 41/2010, de 29 de diciembre, del medio marino (en adelante, LPMM) ${ }^{28}$. La Administración General del Estado también ostenta competencias sobre los espacios naturales protegidos en aguas exteriores (DA $1^{\text {a }}$ LPNB) en relación a la "protección, conservación y regeneración de recursos costeros", estableciendo, por ejemplo, limitaciones y prohibiciones de la actividad pesquera. Finalmente, la Administración General del Estado tiene la obligación de aprobar un inventario español de patrimonio natural (art. 9), que engloba los Espacios naturales protegidos, la Red Natura 2000 y las áreas internacionales (ex art. 9.4). El Estado es competente (declaración y gestión) de las AMPs que se proyecten exclusivamente sobre el medio marino, independientemente de cual sea la figura de protección utilizada ${ }^{29}$. Por su parte, las CC.AA. son competentes para declarar y gestionar las AMPs mixtas.

En definitiva, en los espacios exclusivamente terrestres o simultaneados con el marino, las CCAA serán competentes (arts. 36.1, y 6, letra a LPNB), mientras que, en los espacios exclusivamente marinos, la Administración competente será el Estado (arts. 6 y 36.1 LPNB). Se pone de manifiesto cómo en este ámbito, al igual que sucede en otros, es necesario llevar una integración orgánica y competencial de las CC.AA. costeras a través de los instrumentos de planificación (Plan Estratégico Estatal, estrategias marinas, Planes hidrológicos, resto de planificación sectorial...).

\subsection{La Ley 42/2007 de Patrimonio Natural y de la Biodiversidad como origen y marco general para la protección de las áreas marinas protegidas stricto sensu en España.}

En España, las AMPs como figura de protección, fueron incorporadas a la legislación estatal mediante la LPNB $^{30}$. La Ley 4/1989, de 27 de marzo, de Conservación de Espacios naturales, a la que ésta derogaba, establecía la

\footnotetext{
${ }^{28}$ Modificada por RD 957/2018, de 27 de julio.

${ }^{29}$ La declaración de áreas marinas de competencia estatal se llevará a cabo mediante Real Decreto, a propuesta del Ministerio de Medio Ambiente, previo informe del Consejo Asesor de Medio Ambiente y la Conferencia Sectorial de Pesca.

30 La Ley 4/1989, recogía la posibilidad de declarar espacios protegidos en el mar (arts. 10.1 y 21.3), pero no introducía una figura específica, inclinándose más bien por la protección del espacio terrestre.
} 
posibilidad de crear espacios marinos protegidos (ex arts. 10.1 y 21), pero no determinaba una figura específica para ello. El Titulo II de la LPNB es el encargado de regular la figura de las AMPs, y de crear la Red de AMP (aunque no la desarrolla), en línea con las directrices de la Unión Europea. La norma amplía, también, la posibilidad de crear espacios naturales protegidos transfronterizos, condición que favorece la gestión de áreas marinas protegidas con países limítrofes a España: Portugal, Marruecos, Francia e Italia, principalmente. El medio marino podrá protegerse mediante la definición específica de AMP que establece el art. 33.1 LPNB o por cualquier otra figura de protección prevista en la Ley, como ya hemos dicho; en dicho caso, el régimen de protección será el previsto para cada una de ellas sin menoscabo de que se puedan establecer otros espacios protegidos de carácter sectorial.

El art. 33.1 de la LPNB define a las AMP como:

espacios naturales designados para la protección de ecosistemas, comunidades o elementos biológicos o geológicos del medio marino, incluidas las áreas intermareal y submareal, que, en razón de su rareza, fragilidad, importancia o singularidad, merecen una protección especial ${ }^{31}$.

Por su parte, los espacios naturales protegidos, según el art. 27.2 LPNB:

podrán abarcar en su perímetro ámbitos terrestres exclusivamente, simultáneamente terrestres y marinos, o exclusivamente marinos.

El enfoque precautorio y abierto que tiene esta definición de AMPs obliga a acudir a otras legislaciones específicas para concretar el impacto de esta figura con otros instrumentos como pueden ser, por ejemplo, las "reservas marinas" (art. 14 de la Ley 3/2001, de pesca marítima del Estado) ${ }^{32}$. Así como con otras figuras de protección que recoge la LPNB, como las de la Red Natura 2000, los

\footnotetext{
${ }^{31}$ Las AMPs han sido definidas (ORTíZ GARCÍA) como "una técnica jurídica que otorga un régimen protector especial a un espacio marino -que puede estar vinculado al espacio terrestrey localizado en cualquier espacio oceánico sea jurisdiccional o no, para la salvaguarda de los ecosistemas marinos relevantes y/o amenazados que contenga, mediante la declaración formal del órgano competente de acuerdo con la normativa de conservación de la naturaleza; que, asimismo, posibilitará y regulará los usos que no impidan la capacidad de regeneración del medio, fundamentalmente, actividades de investigación y educativas, así como ciertas prácticas artesanales de pesca". Vid. Ortíz García, M.: La conservación..., op. cit., pp. 129 a 130.

32 Son reservas marinas "aquéllas que por sus especiales características se consideren adecuadas para la regeneración de los recursos pesqueros".
} 
lugares de Importancia Comunitaria (LIC-ZEP), art. 42 .1 LPNB, y las zonas de especial protección para las aves (ZEPAS), art. 43 LPNB; los parques nacionales marinos y terrestres; los parques naturales; las zonas vedadas de pesca (de acondicionamiento y repoblación); y las reservas naturales, monumentos naturales y paisajes (arts. 30 y ss. LPNB). Estas figuras coexisten, además, con otras figuras de protección que son creadas a nivel autonómico y local como pueden ser, por ejemplo, las Reservas Naturales Concertadas en Andalucía (son más de 800 espacios naturales protegidos, por lo general de pequeño tamaño, con otras figuras desarrolladas por las comunidades autónomas).

Según EUROPARC-España ${ }^{33}$, de las figuras de protección recogidas en la LPNB, en España hay 15 parques nacionales, 152 parques naturales, 291 reservas naturales, 342 monumentos naturales, 57 paisajes protegidos y 2 áreas marinas protegidas que tienen una superficie protegida de 4.896 .316 ha, siendo necesario alcanzar los $100.000 \mathrm{Km} 2$ (superficie mayor que la de Andalucía) para cumplir el objetivo de Naciones Unidas previsto para el año 2020 , el $10 \%$ de la superficie total ${ }^{34}$. No obstante, el repaso a las cifras nos permite comprobar que España cumplirá con parte de los compromisos cuantitativas del Convenio para la biodiversidad, al contar con más del $27 \%$ de la superficie terrestre protegida en la Red Natura 2000 y cerca del $13 \%$ de las aguas marinas protegidas incluidas en la Red Natura 2000, en torno a los 84.400 km2, en su mayoría en aguas territoriales, una cuarta parte de la superficie protegida que la Unión Europea tiene incluida en la Red Natura $2000^{35}$, siendo necesario que la Red de Parques Nacionales incremente la superficie marina protegida a través de la ampliación y declaración de nuevas $\mathrm{AMPs}^{36}$.

\footnotetext{
${ }^{33}$ AA.VV.: EUROPARC-España, op. cit., pág. 24.

34 Vid. informe "Propuesta de áreas marinas de importancia ecológica: Atlántico Sur y Mediterráneo español", Oceana y Fundación Biodiversidad en diciembre de 2008 y Alonso García, E.: "Prólogo", en Ortíz García, M.: La gestión eficiente..., op. cit., p. 17.

${ }^{35}$ Véase la meta número 11 del informe "Planeta Protegido 2018" (UNEP-WCMC \& IUCN, 2018) con información actualizada al respecto.

${ }^{36}$ Vid. El informe de Oceana "Parques Nacionales Marinos. Hacia una mejora en la protección del patrimonio natural sumergido de los mares de España", de junio de 2017, que considera necesaria la declaración del primer Parque Nacional exclusivamente marino en aguas atlánticas en El Hierro (Canarias); Ampliación del Parque Nacional de Doñana (Andalucía); Ampliación del Parque Nacional de las Islas Atlánticas (Galicia); Declaración del primer Parque Nacional exclusivamente marino en aguas mediterráneas en las montañas submarinas del Canal de Mallorca (Baleares).
} 


\subsection{Las AMPs, el conocimiento científico aplicado y los instrumentos de inventarización.}

La protección de zonas de alto valor ecológico persigue un enfoque ecosistémico que pretende una gestión completa e integrada (holística) de las actividades humanas, basada en el conocimiento científico existente sobre el ecosistema y su dinámica, con el fin de identificar las acciones negativas que comportan para la salud ambiental de los ecosistemas, y de racionalizar las actividades que se realizan en estos espacios en la disposición de bienes y servicios.

La propia Comisión Europea coordina un grupo de expertos en materia de ordenación del espacio marítimo, denominado Marine Spatial Experts groups (MSEG). También existe una plataforma de asistencia a los Estados miembros donde se comparte información y experiencias (MSP Platform) y el Fondo marítimo europeo (EU Marítime Forum). La necesidad de adaptar la metodología empleada en la recogida y tratamiento de datos ha dado lugar a la creación de la Red Europea de Observación e Información del Mar (EMODnet), en fase de desarrollo, que pretende uniformar el acceso y la obtención de información sobre este medio. España participa en dos proyectos relacionado con la ordenación del espacio marítimo europeo subvencionados por la Comisión Europea a través de proyectos de cooperación con otros países (SIMNORAT y SIMWESTMED) en los que participan el CEDEX, el Centro de Estudios de Puertos y Costas, el Instituto Español de Oceanografía y el Ministerio.

La ejecución de Proyectos tan ambiciosos, ya finalizados, como ESMAREC, DEEPCON, ECOMARG, LIFE INDEMARES, dirigidos a la inventariación y designación de la Red Natura 2000 en Áreas Marinas del Estado Español permitieron gestionar casi 100 AMPs con diferentes categorías de protección, pasando de un $0,5 \%$ a una superficie protegida de las aguas españolas del $8 \%$. Así como otras propuestas efectuadas en proyecto LIFE+PISCES, en el que colaboró WWF, que identificaron hasta un total de 76 áreas representativas para su conservación en el ámbito litoral y marino español; clasificación que resulta meritoria, sobre todo si tenemos en cuenta la escasa y dispersa información científica obrante para algunas de las zonas seleccionadas, priorizando 20 de ellas amenazadas (a las que denomina "paraísos marinos"), de altísimo valor e importancia ecológica 
El Inventario Español de Patrimonio Natural y de la Biodiversidad (art. 51 LPNB) incluye los Espacios Naturales Protegidos, los espacios incluidos en la Red Natura 2000 y las Áreas protegidas por instrumentos internacionales. Este Inventario ${ }^{37}$, junto con el Plan Estratégico Estatal del Patrimonio Natural y la Biodiversidad y los Planes de Ordenación de los Recursos Naturales, constituye una pieza clave para racionalizar y sistematizar el conocimiento e información objetiva y comparable a nivel estatal dada la proliferación de figuras de protección. De esta forma crea el Sistema Integrado de Información, que incluye el Banco de Datos de la Naturaleza, conforme al cuál se permite el análisis y la difusión de la información que consta en el Inventario, que a su vez es completada por organizaciones científicas e independientes.

Por su parte, el Inventario español de hábitats marinos (IEHM) se dirige a informar sobre el estado de conservación de los tipos de hábitats marinos presentes en España, con especial atención a los que precisen medidas específicas de conservación o hayan sido declarados de interés comunitario.

\subsection{La Ley $33 / 2015$, de 21 de septiembre, por la que se modifica la LNPB: la sustancial referencia a la conectividad ecológica.}

La Ley 33/2015, de 21 de septiembre, por la que se modifica la LNPB, pretende mejorar ciertos aspectos técnicos de ésta, especialmente en lo que se refiere a la gestión de espacios naturales protegidos. La inclusión del art. 15, intitulado, "del marco estratégico de la Infraestructura verde y de la conectividad y restauración ecológicas", se dirige a garantizar la conectividad ecológica y la restauración del territorio español, comprometiéndose a elaborar, en un plazo de tres años, una Estrategia estatal de infraestructura verde, y de la conectividad y restauración ecológicas ${ }^{38}$. La Estrategia estatal de infraestructura verde y de la

\footnotetext{
${ }^{37}$ Vid. Real Decreto 556/2011, de 20 de abril.

${ }^{38}$ Se han elaborado los documentos técnicos que constituirán la base de su desarrollo de esta Estrategia. Vid. Valladares, F., Gil, P. y Forner, A. (coord.): Bases científico-técnicas para la Estrategia estatal de infraestructura verde y de la conectividad y restauración ecológicas. Ministerio de Agricultura y Pesca, Alimentación y Medio Ambiente, Madrid, 2017, 357 pp.
} 
conectividad y restauración ecológicas tendrá por objetivo según el art. 15.2 LPNB):

(...) marcar las directrices para la identificación y conservación de los elementos del territorio que componen la infraestructura verde del territorio español, terrestre y marino, y para que la planificación territorial y sectorial que realicen las Administraciones públicas permita y asegure la conectividad ecológica y la funcionalidad de los ecosistemas, la mitigación y adaptación a los efectos del cambio climático, la desfragmentación de áreas estratégicas para la conectividad y la restauración de ecosistemas degradados.

La "continuidad ecológica" aspira a reconocer el hecho de que las CC.AA. litorales protegen espacios terrestres $\operatorname{costeros}^{39}$; $y$, también espacios marinos adyacentes permitiendo desarrollar a los Entes autonómicos instrumentos de conectividad en un plazo máximo de tres años a contar desde la aprobación de dicha Estrategia estatal, conforme a sus propias estrategias (art. 15.4 LPNB). La clave está, como señala ORTíZ GARCÍA, en probar la existencia de la citada "continuidad ecológica" para dirimir la atribución competencial. Tanto es así que se ha declarado la nulidad de dos reglamentos autonómicos (Decreto 369/2015 y Orden de 10 de agosto de 2015 de la Consejería de Medio Ambiente y Ordenación del Territorio, respectivamente) al no acreditarse "mediante la mejor evidencia científica existente", esa "continuidad" por parte de la Comunidad Autónoma andaluza ${ }^{40}$.

Como explica LÓPEZ RAMÓN, la escasa previsión de la legislación autonómica (salvo supuestos aislados y poco detallados) en materia de conservación de la naturaleza y de espacios naturales protegidos a la hora de incluir referencias o desarrollos sobre conectividad y corredores ecológicos explica, quizás, la

\footnotetext{
39 Por ejemplo, la Ley 4/2017, de 13 de julio, del Suelo y de los Espacios Naturales Protegidos de Canarias, cuando dice "La valoración de un espacio natural, a efectos de su consideración como protegido, tendrá en cuenta uno o varios de los siguientes requisitos: b) Constituir una muestra representativa de los principales sistemas naturales y de los hábitats característicos, terrestres y marinos, del archipiélago" (art.176.2).

40 Vid. La STJ de Andalucía, con relación al recurso contencioso-administrativo núm. 22/2016 interpuesto por la Administración General del Estado contra varios reglamentos de la Comunidad Autónoma de Andalucía en los que se declaran espacios marinos y aprueban planes de gestión en hábitats marinos. Vid. Ortíz García, M., "Las áreas marinas protegidas: avances en su conservación", en López Ramón, F. (Coord.) Observatorio de Políticas Ambientales, Centro de Investigaciones Energéticas, Medioambientales y Técnicas (CIEMAT), 2019, (en prensa).
} 
estrategia estatal para tratar de coordinar los instrumentos de conectividad de las Comunidades Autónomas ${ }^{41}$.

La relación entre conectividad y planificación territorial, sectorial y urbanística, en todo caso, implica, qué duda cabe, una mayor coordinación en las políticas de planificación de la naturaleza relevante en las distintas escalas geográficas y niveles administrativos en los que se ordena el territorio, dentro de un proceso multiescalar en cascada ${ }^{42}$. Esta labor de colaboración también debe sustentarse sobre la base de tareas específicas como la emisión de informes, la mejora de los canales de información, la creación de órganos de composición mixta, la adaptación de planes de medidas y, en definitiva, los resultados y realizaciones técnicas, ayudarán a respetar el cumplimiento de principios de eficacia administrativa (art. 103 CE), de lealtad institucional (art. 4 LRJPAC), de "no regresión ambiental" 43 y de respeto por las competencias ajenas, según ha sido reiterado por nuestra jurisprudencia (por todas, la STC 26/1994, de 10 de febrero). La tendencia actual apunta a una superación de enfoques sectoriales, compatibilizando los usos específicos, favoreciendo la consecución de demandas desarrollistas legítimas, o disponiendo de espacios marinos para proveer el abaratamiento energético, la investigación científica y la gestión de espacios marinos transfronterizos.

\subsection{La Ley $41 / 2010$ de Protección del medio marino, como esquema de integración de objetivos.}

La LPMM transpone a la Directiva 2008/56/CE, de 17 de junio de 2008, por la que se establece un marco de acción comunitaria para la política del medio marino (en adelante, $\mathrm{DMEM}^{44}$ ) y regula una serie de aspectos que hasta ahora no se habían abordado en nuestro Derecho. Fundamentalmente tres:

\footnotetext{
${ }^{41}$ Vid. López Ramón, F.: "Conectividad y corredores ecológicos en la experiencia española", Revista Aragonesa de Administración Pública (ejemplar dedicado a: instrumentos territoriales para la protección de la biodiversidad), núm. 16, 2016, pp. 35-61.

42 Vid. Valladares, F., Gil, P. y Forner, A. (coord.): Bases científico-técnicas, op. cit., pág. 27.

43 Únicamente la degradación natural irreversible del espacio natural protegido científicamente demostrada podría justificar su desclasificación. Vid. López Ramón, F.: "El principio de no regresión en la desclasificación de los espacios naturales protegidos en el Derecho español", en Revista Aranzadi de Derecho Ambiental, núm. 20, 2011, pág. 27.

${ }^{44}$ Modificada por la Directiva (UE) 2017/845, de la Comisión de 17 de mayo, en relación a las listas indicativas de elementos que deben tomarse en consideración para elaborar estrategias marinas. Sobre los orígenes de esta política comunitaria, cifr. COM (2005) 504 final. Estrategia temática sobre la protección y la conservación del medio ambiente marino, p. 3.
} 
a) La aprobación de Estrategias Marinas como instrumento de planificación;

b) La incorporación de criterios ambientales en los usos del medio marino.

c) La creación de la Red de Áreas Marinas Protegidas de España (RAMPE).

La LPMM constituye un paso adelante en la estrategia de preservación e integración de los espacios marinos protegidos, sobre todo en lo que a la gestión de las AMPs se refiere e introduce medidas dirigidas a proporcionar un marco general para la planificación y protección del medio marino, consagrando la necesidad de adoptar un enfoque ecosistémico o adaptativo para las aguas marinas. La Directiva establece la obligación para los Estados miembros de adoptar las medidas necesarias para lograr o mantener un buen estado medioambiental del medio marino a más tardar para el año 2020 manteniendo la biodiversidad y el dinamismo de unos océanos y mares limpios, sanos y productivos, cuyo aprovechamiento sea sostenible.

a) Los fundamentos ambientales de la Ley: las estrategias marinas y los criterios técnico-jurídicos del programa de medidas.

La LPMM prevé la aprobación de medidas encaminadas a lograr o mantener el buen estado ambiental del medio marino a través de su planificación, conservación, protección y mejora, al mismo tiempo que reconoce la importancia de preservar el medio marino como parte integrante del dominio público marítimo-terrestre, asegurando un uso sostenible de sus recursos, de acuerdo al interés general que proclama el artículo 132.2 CE.

Con la finalidad de avanzar hacia un buen estado ambiental del medio marino se establecieron las siguientes obligaciones por parte de los Estados miembros:

- Una evaluación inicial de las aguas marinas, con la realización de un análisis del estado ambiental actual, de los principales impactos y presiones, así como del análisis económico, social y del coste que supone el deterioro del medio marino 
- La definición del buen estado ambiental, de acuerdo a los 11 descriptores del buen estado ambiental, para cada subregión marina ${ }^{45}$.

- La propuesta de objetivos ambientales e indicadores asociados para las aguas marinas.

- La elaboración y puesta en marcha de un Programas de medidas, donde se encaminen las actuaciones a emprender con mayor concreción.

- El establecimiento de Programas de seguimiento coordinados, para evaluar establemente el estado ambiental de las aguas marinas

El conjunto de estas obligaciones tiene un impacto mensurable en el la calidad ambiental de las áreas marinas protegidas y en la conservación de la biodiversidad marina.

La LPMM crea un marco general que usa la planificación para coordinar los diferentes sectores y actividades que utilizan como soporte físico el mar, elaborando una estrategia marina para cada demarcación marina: noratlántica, sudatlántica, del Estrecho y Alborán, levantino-balear y canaria. Las estrategias marinas son el instrumento de planificación creado al amparo de la DMEM y tienen como principal objetivo la consecución del buen estado ambiental para el año 2020 y constituyen una base operativa para alcanzar una mayor armonización en relación a la tutela ambiental del medio marino y son el "marco general al que deberán ajustarse necesariamente las diferentes políticas sectoriales y actuaciones administrativas con incidencia en el medio marino, de acuerdo con lo establecido en la legislación sectorial correspondiente" (art. 7 LPMM). Pero como señala la propia LPMM, el desarrollo de estas estrategias marinas no conlleva la modificación ni derogación de la legislación sectorial nacional que resulta de aplicación en el mar (navegación, puertos, pesca

\footnotetext{
${ }^{45}$ El buen Estado ambiental de las aguas marinas constituye la base en que se sustenta en un conjunto de 11 descriptores (desarrollado mediante la Decisión (UE) 2017/848, de 17 de mayo, por la que se establecen los criterios y las normas metodológicas aplicables al buen estado medioambiental de las aguas marinas, así como las especificaciones y métodos normalizados de seguimiento y evaluación, por la que se deroga la Decisión 2010/477/UE. Estos son: 1. Biodiversidad; 2. Especies alóctonas; 3 . Especies explotadas comercialmente; 4. Redes tróficas; 5. Eutrofización; 6. Fondos marinos; 7. Condiciones hidrográficas; 8. Contaminación y sus efectos; 9. Contaminantes en los productos de la pesca; 10. Basuras marinas; 11. Ruido submarino
} 
marítima, hidrocarburos, lucha contra la contaminación en el mar o protección de especies y hábitats), de donde se deduce su función armonizadora.

\section{b) La Red de Áreas Marinas Protegidas (RAMPE)}

Según la UICN, una red de AMPs es "un sistema de AMP o de reservas que funcionan de forma coordinada y sinérgica, a diversas escalas espaciales y niveles de protección concebidos para realizar unos objetivos que no habrían podido lograrse recurriendo a una reserva única". El conjunto de todas las áreas marinas protegidas constituye la Red de áreas marinas protegidas españolas (en adelante, RAMPE), regulada en la LPNB, aunque desarrollada en la LPMM. La RAMPE, integra espacios de protección situados en el medio marino español con independencia de que su declaración y gestión estén reguladas por normas internacionales, comunitarias y estatales; así como el marco normativo y el sistema de relaciones necesario para su funcionamiento ${ }^{46}$.

Para integrarse en la RAMPE, los espacios deben cumplir los requisitos del Real Decreto 1599/2011, de 4 de noviembre, por el que se establecen los criterios de integración. Como aclara el art. 26.3 LPMM, se podrán incluir los espacios naturales protegidos de competencia autonómica que cumplan con los criterios de representatividad; carácter único o rareza; importancia para el hábitat o especies amenazadas, en peligro, en declive o regresión; por su grado de naturalidad; de productividad biológica; de vulnerabilidad o fragilidad; de contribución a la conectividad. La clasificación de estos requisitos atiende a una caracterización natural de los espacios, más allá de su división administrativa o por sectores estratégicos.

La RAMPE busca una mayor interrelación y equilibrio de los objetivos que estas zonas individualmente persiguen, asegurando la conservación y recuperación del patrimonio natural y la biodiversidad marina; protegiendo y conservando las áreas que mejor representan el rango de distribución de las especies, hábitat y procesos ecológicos en los mares; o fomentando la conservación de corredores ecológicos (art. 25 de la LPPM).

\footnotetext{
${ }^{46}$ Sobre esta cuestión, vid. Ortíz García, M.: "La red de áreas marinas protegidas de España en la protección del medio marino", en Arana García, E. y Sanz Larruga, F.J. (Dirs.): La ordenación jurídica del medio marino en España, Civitas, Cizur Menor (Navarra), 2012, pp. 333-380.
} 
En comparación con un AMP única de grandes dimensiones, una red formada por AMPs más pequeñas dispone como ventaja el tener una mayor flexibilidad para mitigar los impactos de actividad y puede tener mayor funcionalidad social en la medida en que las responsabilidades de gestión, las políticas comunes de ordenación, las metas de eficiencia económica y las oportunidades de aprendizaje pueden ser compartidas ${ }^{47}$.

El art. 22 de la LPMM, por su parte, crea dos órganos ad hoc: por un lado, la Comisión Interministerial de Estrategias Marinas (la denominada CIEM), cuyas funciones en la elaboración, aplicación y seguimiento de la planificación del medio marino recuerdan a las competencias que tiene atribuidas el Comité de Autoridades Competentes (como órgano encargado de mejorar la coordinación interadministrativa en la gestión y planificación de las aguas litorales); y por otro, los Comités de Seguimiento de las Estrategias Marinas, cuya función se basa en la ejecución de la estrategia correspondiente para el seguimiento de la aplicación de las estrategias marinas. Esto, en definitiva, supone una forma de colaboración interadministrativa, y se une a otras formas ya tradicionales de cooperación y coordinación entre Administraciones como la Conferencia Sectorial del Medio ambiente, o la creación del Comité de Autoridades Competentes en el ámbito de la demarcación hidrográfica.

\section{c) El plan integral de protección de Áreas Marinas Protegidas}

El Plan Integral de áreas marinas protegidas, recogido en la LPMM, constituye un instrumento básico de coordinación para la gestión de la Red de Áreas Marinas Protegidas. El Plan, que cuenta con una vigencia máxima de diez años, incluye los objetivos estratégicos de la Red, así como otra información de interés relativa a la misma (directrices para la planificación de la Red, programa de actuaciones, determinación de proyectos, etc.). Su aprobación contribuye a crear un marco de funciones de esta Red (no de cada una de las áreas protegidas que

\footnotetext{
${ }^{47}$ Vid. AA.VV.: Estudio sobre la implementación de nuevas Áreas Marinas Protegidas en las aguas interiores de la Reserva de la Biosfera de Menorca, así como su gestión y recuperación, I-fish consulting \& market s.I, p. 28.
} 
contiene) que recae en la Administración General del Estado dotando de cierta uniformidad a las mismas, como se desprende del art. 28 de la LPMM.

Entre los indicadores que se incluyen en el Anexo del Acuerdo del Consejo de Ministros de 7 de junio de 2019, por el que se aprueban los objetivos ambientales del segundo ciclo de las estrategias marinas españolas ${ }^{48}$, están la aprobación del Plan Director de la RAMPE y la ampliación del porcentaje de Espacios marinos protegidos en la Red ${ }^{49}$. Este Plan es importante en la medida que la mayoría de los espacios marinos protegidos españoles se corresponden con figuras de protección en el marco de la Red Natura 2000 (LIC, ZEC y ZEP).

\section{LA INTEGRACIÓN DE LAS ÁREAS MARINAS PROTEGIDAS EN OTROS INSTRUMENTOS DE PLANIFICACIÓN AMBIENTAL Y SECTORIAL}

La protección de los espacios marinos no se limita a la declaración de áreas marinas protegidas, sino que integra un conjunto de estrategias vinculadas a instrumentos de planificación ambiental y sectorial.

\subsection{Las AMPs en el ámbito de gestión de la política marítima integrada.}

Existe la necesidad de coordinar las actividades y usos marítimos con la protección ambiental del medio marino. La política marítima integrada pretende ordenar las diferentes estrategias sectoriales, que, impulsadas desde el seno de la Unión Europea, actúan en el litoral y van dirigidas a proteger nuestros mares

\footnotetext{
${ }^{48}$ Vid. Resolución de 11 de junio de 2019, de la Secretaría de Estado de Medio Ambiente.

49 A nivel autonómico andaluz, tcabe destacar, a la RENPA (Red de Espacios Naturales Protegidos de Andalucía) que compone un sistema integrado de todos los espacios naturales ubicados en el territorio andaluz que gocen de un régimen especial de protección en virtud de normativa autonómica, estatal y comunitaria, o convenios y normativas internacionales, y pueden incardinarse, total o parcialmente, en otras redes similares de ámbito territorial superior, como la RAMPE o las Listas internacionales. Dicha Red está considerada la más importante en superficie y en número de espacios protegidos de la Unión Europea, abarcaen su conjunto un total de 310 espacios naturales protegidos (249 áreas sin solapamientos) con una superficie del orden de 2,8 millones de has, de las que 2,7 millones son terrestres (lo que representa aproximadamente el $30,5 \%$ de la superficie de Andalucía) y el resto son marinas.
} 
y océanos ${ }^{50}$. La Directiva 2014/89/UE ${ }^{51}$, tiene como objeto (art. 1) llevar a cabo la ordenación del espacio marítimo con vista a fomentar el desarrollo sostenible de las economías marítimas, el desarrollo sostenible de los espacios marinos, así como el aprovechamiento sostenible de los recursos marinos. Conforme a esta declaración de objetivos, la Directiva se dirige a establecer planes de ordenación marítima (art. 8) en los que se concreten la distribución espacial y temporal de las correspondientes actividades y usos, presentes y futuros, que se proyectan en este espacio: acuicultura, pesca, instalaciones e infraestructuras de prospección, explotación y extracción de recursos energéticos y materias primas (petróleo, gas, áridos, producción de energía procedente de fuentes renovables, etc.), las rutas de transporte marítimo y el control de los flujos de tráfico, la investigación científica, el cableado y las tuberías submarinas, la protección del patrimonio cultural subacuático, la investigación científica, las zonas de entrenamiento militar. Así como la delimitación de los lugares de conservación de la naturaleza y de las especies y las zonas protegidas ${ }^{52}$.

Entre los objetivos ambientales del segundo ciclo de Estrategias Marinas para las cinco demarcaciones marinas españolas, se encuentra el de "lograr una red completa, ecológicamente representativa, coherente y bien gestionada de las áreas marinas protegidas que tengan en cuenta los descriptores ambientales que incluyen las estrategias marinas.

En definitiva, la estrategia de planificación pretende racionalizar los usos y actividades tratando de paliar los efectos negativos que se derivan de una regulación sectorial y fragmentada, pues, como se ha afirmado ${ }^{53}$.

\footnotetext{
50 Una política eficaz y coherente debe tener en cuenta "la vulnerabilidad de los ecosistemas acuáticos situados cerca de las costas y estuarios, o en golfos o mares relativamente cerrados puesto que el equilibrio de todas estas zonas depende en buena media de la calidad de las aguas continentales que fluyen por ellas". Cfr. Considerando 17 de la DMA.

${ }^{51}$ del Parlamento Europeo y del Consejo de 23 de julio de 2014, por la que se establece un marco para la ordenación del espacio marítimo

52 La Directiva 2014 tiene su origen en La COM (2007) 574 final, que fija las líneas maestras de la política marítima integrada trasladando al medio marinos los objetivos de la "Estrategia Europea 2020". Este documento aspira a alcanzar una actuación coordinada que impulse el desarrollo sostenible a fin de encajar las diferentes políticas sectoriales e identifica dos instrumentos que deben servir de base a este objetivo: en primer lugar, la red europea de vigilancia marítima (en relación a la seguridad y las fronteras marítimas); y, en segundo lugar, la Gestión Integrada de Zonas Costeras y las Políticas Marítimas Integradas (con respecto a la gestión de usos en el espacio marítimo) ordenando la interdependencia de actividades antrópicas que se proyectan en la orla litoral: turismo, infraestructuras, pesca, energía, transportes, etc.

${ }^{53}$ Vid. AA.VV.: Un océano de oportunidades. Una política marítima integrada para la Unión
} 
El Real Decreto 363/2017, de 8 de abril, por el que se establece un marco para la ordenación del espacio marítimo, transpone esta Directiva de 2014 al derecho español y desarrolla el art. 4.2 de la LPMM $^{54}$, desarrollando, sin embargo, a través de una única norma reglamentaria, lo que resulta criticable, dos Directivas: 2008/66/CE y 2014/89/CE ${ }^{55}$. Los objetivos de esta norma se definen para cada demarcación marina, teniendo en cuenta las estrategias marinas y la planificación sectorial resultante al efecto. No obstante, el Real Decreto establece el procedimiento de elaboración de los planes de ordenación y determina el calendario para la aprobación de los mismos (uno por cada demarcación marina) ${ }^{56}$, proponiendo una estructura para desarrollar un crecimiento sostenible de las economías marítimas, así como el desarrollo estable y controlado de los recursos marinos.

\subsection{Las AMPs en las políticas de Gestión Integrada de Zonas Costeras y de protección y uso sostenible del litoral.}

La entrada en vigor del Protocolo relativo a la Gestión Integrada de Zonas Costeras (en adelante, GIZC) del Mediterráneo el 24 de marzo de 2011 estableció un marco regional común para la GIZC en el Mediterráneo con el fin de poner en práctica planes de acción regional y otros instrumentos operacionales, así como desarrollar la protección y conservación de los espacios naturales marinos ${ }^{57}$. Mediante la ratificación del mismo, las Partes se comprometen a cumplir las obligaciones que el mismo recoge.

\footnotetext{
Europea, Oficina de publicaciones oficiales de las Comunidades Europeas, Comisión Europea, Luxemburgo, 2007, p. 5.

${ }^{54}$ En desarrollo del artículo 4.2 de la LPMM, que establece que el Gobierno podrá aprobar directrices comunes a todas las estrategias marinas con el fin de garantizar la coherencia de sus objetivos, en aspectos tales como (en su punto f) la ordenación de las actividades que se llevan a cabo o pueden afectar al medio marino.

${ }^{55}$ Que parten de objetivos distintos y no siempre resultan coincidentes: esto es, la protección del medio ambiente marino, la primera; y el desarrollo de sectores vinculados al medio marítimo, la segunda. Vid. Zamorano Weiss, J.: "La ordenación de los espacios marinos en la Unión Europea", en Revista Aranzadi de Derecho ambiental, núm. 39, 2018.

${ }^{56}$ Vid. Sanz Larruga, Francisco Javier: "La planificación ambiental se vuelca en el mar: la nueva ordenación del espacio marítimo", en Revista Aranzadi de Derecho Ambiental, núm. 37, 2017; y. "La nueva ordenación del espacio marítimo: análisis del Real Decreto 363/2017, de 8 de abril", en Práctica urbanística: Revista mensual de urbanismo, núm. 150, 2018.

${ }^{57}$ El Protocolo en su art. 2.f) señala así que la gestión integrada de zonas costeras debe actuar como "un proceso dinámico de gestión y utilización sostenible de las zonas costeras, teniendo en cuenta simultáneamente la fragilidad de los ecosistemas y paisajes costeros, la diversidad de las actividades y los usos, sus interacciones, la orientación marítima de determinados usos y
} 
Unos años más tarde, la Propuesta de Directiva del Parlamento Europeo y del Consejo por la que se establece un marco para la ordenación del espacio marítimo y la gestión integrada de las zonas costeras ${ }^{58}$, avanza en el proceso programático de la Recomendación 2002/413/CE, sobre la aplicación de la gestión integrada de las zonas costeras en Europa. La Propuesta pretende fusionar los planes de ordenación marítima y las estrategias de gestión integrada de las costas, dentro de una "política marítima integrada", considerando que ambos son instrumentos complementarios, ya que se centran, respectivamente, en las actividades humanas existentes y potenciales a efectos de la elaboración de planes de ordenación marítima en las aguas marinas y en identificar las medidas para la gestión integrada de tales actividades humanas en las zonas costeras. Por ello entiende que la aplicación coherente y conjunta de los planes de ordenación marítima y de las estrategias integradas de gestión de las costas contribuirá a mejorar la planificación y la gestión de la interfaz tierra-mar, jugando (previsiblemente) un papel integrador con respecto al régimen de las aguas de transición.

De esta forma, una de las vías utilizadas para avanzar hacia una gestión integrada del litoral ha sido el desarrollo de instrumentos de planificación y gestión que aspiran a conectar los aspectos legales con su realidad ecológica.

\subsection{Las AMPs en el contexto de las políticas de gestión integrada del agua: la protección ambiental de las aguas costeras y de transición.}

Una parte importante de los objetivos que persigue la declaración de AMPs depende de la integración de políticas de protección del medio marino y de gestión integrada de los recursos hídricos, pues, como se sabe, hasta el $80 \%$ de la contaminación que se localiza en el medio marino se produce por vía terrestre ${ }^{59}$.

determinadas actividades, así como sus repercusiones a la vez sobre la parte marina y la parte terrestre".

58 Vid. COM (2013) 133 final.

59 El $70-75 \%$ de la contaminación marina global es producto de las actividades humanas que tienen lugar en la superficie terrestre. Vid. Escobar, J.: La contaminación de los ríos y sus efectos en las áreas costeras y el mar, CEPAL: recursos naturales e infraestructuras, Publicación de las Naciones Unidas, Santiago de Chile, 2002, p. 5. 
El Texto Refundido de la Ley de Aguas aprobado por el Real Decreto Legislativo 1/2001, de 20 de julio, (en adelante, TRLA), transpuso en 2003 a la Directiva 2000/60/CE, de 23 de octubre de 2000 (en adelante, DMA). Como hito del Derecho europeo, la DMA reconoce la necesidad de avanzar hacia una verdadera gestión integral de las aguas, introduciendo la regulación de la calidad ambiental de las aguas costeras y de transición, y el buen estado químico de las aguas del mar territorial, actuando como un elemento funcional, pero interrelacionado, en la preservación ambiental de las AMPs.

La DMA se dirige a prevenir todo deterioro del estado (ecológico y estado químico)de las masas de agua superficial, subterráneas, costeras y de transición; así como alcanzar el "buen potencial ecológico y el buen estado químico" de todas las masas de agua artificiales y muy modificadas (como pueden ser las aguas confinadas en los puertos o algunas masas de agua costeras sometidas a fuertes alteraciones hidromorfológicas); reduciendo, progresivamente, la contaminación producida por las sustancias prioritarias, eliminar los vertidos, las emisiones y las pérdidas de sustancias peligrosas prioritarias.

Las aguas de transición y costeras quedan integradas dentro del ámbito de la demarcación hidrográfica, la unidad de gestión ambiental de los recursos hídricos $^{60}$. Cada una de las veinticinco demarcaciones hidrográficas existentes en España conecta físicamente con una de las cinco demarcaciones marinas que establece la LPMM. La LPMM, en este sentido, determina en su Preámbulo que transpone literalmente a la DMEM cuando fija su ámbito de aplicación a las aguas marinas que estén bajo soberanía o jurisdicción española, incluyendo el lecho, el subsuelo y los recursos naturales que éstas albergan (art. 2); pero especifica que su contenido no afectará a las aguas costeras definidas en el art. 16 bis del TRLA, referente a la demarcación hidrográfica, en relación con aquellos aspectos del estado ambiental del medio marino que ya estén regulados en el citado TRLA o en su desarrollo reglamentario. Esta coordinación normativa,

\footnotetext{
${ }^{60}$ Esta demarcación hidrográfica se define, en el art. 16 bis TRLA como "la zona terrestre y marina compuesta por una o varias cuencas hidrográficas vecinas y las aguas de transición, subterráneas y costeras asociadas a dichas cuencas" y viene a modificar el ámbito territorial de los nuevos Planes hidrológico que han de ser preceptivamente aprobados en cada una de estas demarcaciones hidrográficas, ampliando, a efectos de la calidad ambiental, su ámbito territorial hasta el límite exterior de las aguas costeras.
} 
latente en otras partes de la Ley ${ }^{61}$, implica la aplicación subsidiaria de la LPMM sobre las aguas costeras en aspectos de la calidad de estas aguas que no hayan sido convenientemente tratados.

Las aguas costeras (que alcanzan la distancia de una milla náutica desde la costa a partir de las líneas de base recta que sirven para medir el mar territorial) demarcan el límite exterior de la demarcación hidrográfica (art. 16 bis TRLA) y, por tanto, el ámbito territorial de cada Plan hidrológico (art. 40.3 TRLA). El ámbito de aplicación territorial de las estrategias marinas comienza donde terminan los Planes hidrológicos de demarcación ${ }^{62}$ y hasta una anchura de 200 millas náuticas que marca la zona económica exclusiva. Conforme a su propia regulación, no obstante, las estrategias marinas podrán regular aspectos de la calidad ambiental de las aguas costeras, pero no podrán contradecir lo establecido en los Planes hidrológicos de la demarcación ${ }^{63}$.

La metodología exhaustiva de la DMA (Anexo II) introduce un análisis riguroso basado en aspectos ambientales (clasificación de las masas de agua, planes de medidas, participación pública, programas de seguimiento...) que impulsa un mayor poder fiscalizante o "disciplinante" a favor de las instituciones europeas (Comisión y TJUE) ${ }^{64}$. Por el contrario, sus contenidos técnicos superan, en muchos casos, el discernimiento de aquéllos a quienes les corresponde controlar su cumplimiento, actuando como una evidencia científica en la línea de producción normativa del Derecho ambiental comunitario ${ }^{65}$ que, incluso, ha hecho que se plantee si la DMA puede llegar a ser una norma de cumplimiento

61 Como sucede, además de con el TRLA, con la Ley de Costas, la Ley 42/2007, de 13 de diciembre, del Patrimonio Natural y de la Biodiversidad, la Ley 3/2001, de 26 de marzo, de Pesca Marítima del Estado, la Ley 26/2007, de 23 de octubre, de Responsabilidad Medioambiental, u otras referencias genéricas a la legislación de navegación, puertos, lucha contra la contaminación en el mar, protección de especies y hábitats, al sector turístico y de hidrocarburos, etc.

62 De Ley 10/1977, de 4 de enero, sobre el Mar Territorial, esta línea de base es mixta y está compuesta por la línea de bajamar escorada y por las líneas de base rectas definidas en el artículo 1 del Real Decreto 2510/1977, de 5 de agosto, sobre trazado de líneas de base recta en desarrollo de la Ley 20/1967, de 8 de abril, sobre extensión de las aguas jurisdiccionales españolas a 12 millas, a efectos de pesca.

${ }^{63}$ Ello, pese a lo que afirma la LPMM: "las políticas sectoriales que se lleven a cabo o puedan afectar al medio marino serán compatibles o se adaptarán a los objetivos de las estrategias marinas (art. $4.1 \mathrm{~h}) "$

64 Vid. López Menudo, F.: “Las aguas", en Revista de Administración Pública, núm. 200, 2016, p. 254.

65 Vid. Biondi, A. et. Al. (Eds.): "Scientific evidence in European Environmental rule-making", en Kluwer law international, La Haya (Holanda), 2003. 
imposible en España ${ }^{66}$ debido a las altas exigencias que se pueden derivar del respeto a las condiciones ambientales de los ríos y las limitaciones que afectan a la gestión de la oferta y demanda.

El art. 2.3 de la LPMM (encargado de fijar el ámbito de aplicación de la Ley), aclara que las diferentes estrategias marinas "no serán de aplicación a las aguas costeras definidas en el artículo 16 bis del TRLA, en relación con aquellos aspectos del estado ambiental del medio marino que ya estén regulados en el citado TRLA o en sus desarrollos reglamentarios" 67 , aunque puntualiza en su inciso final "debiéndose cumplir, en todo caso, los objetivos ambientales establecidos en virtud de la presente ley y en las estrategias marinas que se aprueben en aplicación de la misma".

A pesar de que existe una aproximación respetuosa entre ambas normativas y, aunque parece clara la prevalencia de la planificación hidrológica sobre las estrategias marinas, sería deseable una mayor concreción jerárquica. La clave de esta integración, como se ha dicho, se encuentra en el grado de participación y coordinación que puede alcanzarse en la elaboración de los Programas de medidas $^{68}$, para evitar que respondan al ejercicio aislado de las competencias que se proyectan sobre un mismo medio físico ${ }^{69}$.

La prevalencia de un tipo de planificación u otro constituye uno de los aspectos a aclarar en razón del principio de seguridad jurídica. No sólo qué instrumento de planificación tiene preferencia, sino cuándo, cómo y por qué. Y es que las estrategias marinas se han de integrar de forma coherente, no sólo con la

\footnotetext{
66 Vid. Caro-Patón, I. y Escartín Escudé, V.: "Aguas: Por una política hidráulica más reflexiva, transparente y participativa", en López Ramón, F.: Observatorio de Políticas Ambientales, 2015, p. 522.

${ }^{67}$ Como también señala en el Preámbulo de la LPMM "en el caso de las aguas costeras, dado que la aplicación de la Directiva marco del agua en España ya contempla la garantía de la consecución del buen estado, la LPMM sólo se aplicará en los aspectos de la protección o la planificación del medio marino que no se hayan contemplado en los Planes hidrológicos de cuenca".

${ }^{68}$ En este sentido, Núñez Lozano, M.C. y Zamorano Wisnes, J.: "Ordenación de los espacios marítimos, gestión integrada de zonas costeras y planificación hidrológica”, en AA.VV.: Iniciativas en Iberoamérica de interés para la gestión integrada de áreas litorales (Actas del I Congreso Iberoamericano de Gestión Integrada de Áreas Litorales), Cádiz, 2012, pp. 1758 y 1759.

${ }^{69} \mathrm{El}$ art. 40.2 del TRLA que establece que "(I)a política del agua está al servicio de las estrategias y planes sectoriales que sobre los distintos usos establezcan las Administraciones públicas, sin perjuicio de la gestión racional y sostenible del recurso que debe ser aplicada por el Ministerio de Medio Ambiente, o por las Administraciones hidráulicas competentes, que condicionará toda autorización, concesión o infraestructura futura que se solicite".
} 
legislación de aguas, sino también con el desarrollo reglamentario de otras normativas sectoriales de gran impacto social y económico en nuestro país: puertos, pesca, energía, protección de especies amenazadas marinas, control de los vertidos desde buques o aeronaves, protección de espacios protegidos, etc. ${ }^{70}$.

Por todo, sería conveniente contar, como se ha advertido, con algún sistema o mecanismo de Derecho interno que sirva para constatar cuando los Planes hidrológicos de demarcación no han alcanzado los objetivos propuestos y que permita aplicar entonces, de forma complementaria, la LPMM y los instrumentos de planificación que ésta propone ${ }^{71}$.

El detalle que plantea la identificación, caracterización, evaluación y seguimiento de la calidad ecológica de las masas de agua en los planes hidrológicos de demarcación, dificulta la coordinación de las exigencias ambientales que establece la norma comunitaria con otras actuaciones sectoriales. Se ha criticado $^{72}$, con razón, la regla de prevalencia (ex art. 19.3 de la Ley 42/2007, de 13 de diciembre) a favor de los Planes de Ordenación de Recursos Naturales (PORN) sobre cualquier otro instrumento planificador sectorial, incluidos los planes hidrológicos, siempre que no se trate de obras de interés público de primer orden o interés general superior. Esta regla, declarada constitucional (SSTC 154/2015 y 182/2015, de 25 de septiembre y 6 de noviembre, respectivamente), sin perjuicio de su derogación singular por razones imperiosas de interés público (STC 154/2015, FJ 4), interpretada literalmente, conlleva una prevalencia de facto de la competencia autonómica (protección de espacios naturales) frente a la competencia estatal (planificación hidrológica u otras). Los efectos que introduce esta prevalencia deben, en cualquier caso, ser matizados,

\footnotetext{
70 Todo ello sin olvidar, además, que la LPMM se remite supletoriamente a la legislación de costas en lo que se refiere a la naturaleza y al régimen de medio marino.

${ }^{71}$ Vid. Dictamen núm. 91/2010, del Consejo de Estado, pág. 53. El Dictamen del Consejo de Estado tiene su reflejo en la disposición adicional quinta de la LPMM que establece que se aplicará la norma de mayor protección ambiental a las aguas costeras cuando la legislación de aguas y, en particular, la planificación hidrológica, respecto de las aguas costeras, no contemple medidas para alcanzar los objetivos ambientales establecidos en la LPMM o en sus normas de desarrollo, o bien dichas medidas sean insuficientes para alcanzar dichos objetivos, siendo posible la aplicación de la LPMM y sus normas de desarrollo cuando, en todo caso, la protección ambiental en dichas aguas sea más exigente.

72 Vid. Fanlo Loras, A.: "Coordinación y prevalencia de la planificación hidrológica en materia de espacios naturales protegidos”, en Revista Española de Derecho Administrativo, núm. 182, 2017, pp. 59-80.
} 
sin actuar como una regla general. Pero no hay que desdeñar el efecto que puede suponer que, por ejemplo, un PORN fije un régimen de caudales ecológicos ${ }^{73}$ para un tramo específico de un río o un área marina protegida.

La protección de espacios singulares no pasa, a nuestro juicio, por realizar propuestas aisladas que establezcan una gestión autónoma o "más esforzada" de los mismos, sino que se debe abordar su protección en desarrollo de los instrumentos de coordinación y colaboración interadministrativos que posibiliten una gestión integrada. La planificación hidrológica sigue siendo, a todas luces, el instrumento orgánico y funcional de referencia puesto que contempla la gestión cuantitativa o cualitativa de los recursos hídricos. Lo contrario puede supone la torsión, e incluso ruptura, de los principios de unidad del ciclo hidrológico, de unidad de cuenca y de unidad de gestión.

\subsection{Las AMPs y su vinculación material con otras regulaciones sectoriales.}

La integración orgánica de las autoridades implicadas en la gestión de la costa debe ir acompañada de una integración funcional que ponga en funcionamiento los mecanismos que inciden en la regulación de las áreas marinas protegidas. Diferentes estrategias comunitarias persiguen el buen estado ecológico o buen potencial ecológico de los elementos biológicos y químicos que se proyectan sobre las costas y estuarios de la Unión Europea, tratando de reducir las presiones que se ejercen por cambios hidromorfológicos o por contaminación telúrica. En este sentido, encontramos Directivas comunitarias como la DMA, la Directiva sobre nitratos, la Directiva sobre el tratamiento de las aguas residuales urbanas, la Directiva sobre las aguas de baño, la Directivas sobre aves y sobre hábitats de la Unión Europea, etc.

\footnotetext{
${ }^{73}$ Vid. Pallarés Serrano, A.: "Estudio sobre la prevalencia de los valores ambientales en la interrelación entre los planes hidrológicos de cuenca y los instrumentos de protección de los espacios naturales", en NAVARRO CABALLERO, T.M. (Dir.): Desafíos del Derecho de aguas. Variables jurídicas, económicas, ambientales y de Derecho comparado, Aranzadi, Cizur Menor, 2016, págs. 237-251.
} 
De otro lado, encontramos las políticas dirigidas a la contención del cambio climático y a la prevención y mitigación de riesgos naturales, que encuentran en la costa un importante campo de actuación ${ }^{74}$.

A nivel sectorial, la LPNB está conectada con normas básicas como el Texto Refundido de la Ley de Puertos del Estado y de la Marina Mercante ${ }^{75}$, la Ley de Pesca Marítima del Estado ${ }^{76}$, el TRLA, la Ley de Costas $^{77}$, etc.

En el ámbito autonómico destacan, sobre todo, las competencias sectoriales, en materia de ordenación del territorio, y competencia de desarrollo para legislar en materia de medio ambiente. Pero también otras políticas sectoriales como el turismo, la agricultura y el urbanismo de masas tienen gran impacto en la conservación de estos espacios, provocando y/o acelerando los fenómenos de inundación, aparición de especies invasoras, eutrofización, salinización, subsidencia, que por sí solos o de forma acumulada, pueden generar un alto impacto ambiental (caso de lo sucedido en la laguna del Mar Menor, en Murcia).

La conservación de las AMPs y de sus valores naturales se decide en la aplicación de los planes o instrumentos de gestión que establezcan, al menos, las medidas de conservación necesarias y las limitaciones de explotación de los recursos naturales que procedan para cada caso, y para el conjunto de las áreas incorporadas a la Red de Áreas Marinas Protegidas (art. 33.2 LPNB).

La superposición de Planes sectoriales con similar ámbito de ejecución y distintos objetivos, puede inducir a confusión y aun desdoblamiento de las políticas públicas. Así, desde el plano ambiental, encontramos, entre otros, instrumentos de ordenación tan variados como el Plan Estratégico Estatal de Patrimonio Natural (arts. 12 y 14); los Planes de Ordenación de los Recursos Naturales (arts. 15 y ss.); el Plan Director de la Red de Áreas Marinas Protegidas (art. 29 de la Ley 41/2010), planes en materia de vertidos, de paisaje, planes

\footnotetext{
${ }^{74}$ Vid. Navarro Ortega, A.: "La alteración de la dinámica litoral fluvial y marina y su controvertido impacto en el medio: un planteamiento de revisión jurídico-administrativo de los riesgos inducidos ante el escenario de incertidumbre científica y de cambio climático", en Arana García, E. (Dir.): Riesgos Naturales y Derecho: una perspectiva interdisciplinar, Dykinson, Madrid, 2018, pp. 267297.

${ }^{75}$ Real Decreto Legislativo 2/2011, de 5 de septiembre,

${ }^{76}$ Ley $3 / 2001$, de 26 de marzo

${ }^{77}$ Ley 22/1988, 28 julio, de Costas, modificada por la Ley 2/2013, de 29 de mayo, de protección y uso sostenible del litoral.
} 
hidrológicos, estrategias marinas, etc.; a ellos hay que sumar los planes de carácter sectorial (puertos, pesca, ordenación del territorio, gestión integrada de zonas costeras, energía...). En respeto a la coherencia y conectividad de las AMPs, las Administraciones públicas deben fomentar, según el art. 47 LPNB:

la conservación de corredores ecológicos y la gestión de aquellos elementos del paisaje y áreas terrestres y marinas que resultan esenciales o revistan primordial importancia para la migración, la distribución geográfica y el intercambio genético entre poblaciones de especies de fauna y flora silvestres, teniendo en cuenta los impactos futuros del cambio climático.

Estableciendo normas de prevalencia claras que se concreten en el correspondiente "programa de medidas" y demás contenidos normativos de cada Plan, favoreciendo una verdadera Gestión Integrada de Gestiones Integradas $\left(\right.$ GIGGII) ${ }^{78}$.

\subsection{El carácter singular de las áreas marinas protegidas en España.}

En este epígrafe exploramos la singularidad de los espacios marinos protegidos en España ${ }^{79}$. Hasta la declaración de la AMP de "El Cachucho", que constituye la primera AMP declarada exclusivamente marina, todas las AMPs declaradas en España tenían una naturaleza mixta que integra espacios de tierra y mar, estando gestionadas mayoritariamente por las Comunidades Autónomas. Más recientemente ha sido declarada otra AMP exclusivamente marina, el corredor de migración de cetáceos del Mediterráneo, aprobada mediante el Real Decreto 699/2018, de 29 de junio, que establece un régimen de protección preventiva y se propone su inclusión en la Lista de Zonas Especialmente Protegidas de Importancia para el Mediterráneo (Lista ZEPIM) en el marco del Convenio de Barcelona. Localizadas en las aguas de la Zona Económica Exclusiva española, ambas son gestionada por el Estado.

\footnotetext{
${ }^{78}$ Sobre este concepto, se puede consultar mi artículo "La protección integrada del medio marino a través de la directiva marco de aguas y su impacto en el derecho español. Los instrumentos de planificación y gestión”, en Arana García, E. y Sanz Larruga, F.J. (Dirs.): La ordenación jurídica del medio marino en España, Civitas, Cizur Menor (Navarra), 2012, pp. 413-455.

${ }^{79}$ Véase un análisis desde la perspectiva del sector pesquero, en Pascual Fernández, J.J. y De La Cruz Modino, R.: "Los espacios marinos protegidos en España: ¿nuevas formas institucionales para las estrategias de apropiación?", en Beltrán, O, Pascual, J.J. y Vaccaro, I. (Coord.): Patrimonialización de la naturaleza. El marco social de las políticas ambientales, pp. 199-221, disponible en: http://www.ankulegi.org/wp (octubre de 2019).
} 
Desde la declaración en 1978 el Parque Natural el Cabo de Gata-Níjar, el primer espacio marino protegido en España, se han ido incluyendo nuevos espacios de gestión. Sin embargo, las últimas propuestas se dirigen a visibilizar la necesidad de proteger los espacios exclusivamente marinos, (proponiendo la inclusión de áreas del Sistema de cañones submarinos, el Canal de Menorca, Volcanes de fango del golfo de Cádiz y Banco de Galicia, realizada en octubre de 2013; o tratando de incorporar otros cinco espacios marinos (Sistema de cañones submarinos de Avilés, Sur de Almería-Seco de los Olivos, Espacio marino de Alborán, Espacio marino de Illes Columbretes y Banco de la Concepción, en 2014).

En fechas más recientes, se ha producido la ampliación del Parque Nacional Marítimo-Terrestre del Archipiélago de Cabrera (Baleares), por el que se amplían los límites del Parque Nacional Marítimo-Terrestre del Archipiélago de Cabrera a través de la incorporación de espacios marinos colindantes al mismo, pasando a proteger una superficie 9 veces mayor (de 10.000 a 90.974 ha) ${ }^{80}$.

Por su riqueza natural, "El Cachucho" cumple los criterios como LIC y ZEC de la Red Natura 2000; cumple también con los criterios necesarios para su inclusión en la Red de Áreas Marinas Protegidas del Convenio OSPAR. Situada en el mar Cantábrico, a unos 65 kilómetros de la costa asturiana de Ribadesella, el caladero de "El Cachucho" es una montaña submarina con un rango de profundidad va desde los más de 4000 metros de profundidad de la llanura abisal del golfo de Vizcaya, hasta los 425 metros que coronan su cumbre. Separado por una cuenca interna de la franja costera, es una zona de gran diversidad biológica que agrupa a unas 682 especies, 5 de las cuales resultaban hasta hace poco desconocidas para la ciencia ${ }^{81}$.

De este modo, el Real Decreto 1629/2011 aprobó las correspondientes medidas de conservación del espacio marino protegido, contenidas en un Plan de gestión común para ambas figuras de protección: AMP y ZEC (Anexo II). Dicho Plan, contiene, entre otras especificaciones, los objetivos y medidas para cada especie, la caracterización del medio y la regulación de usos y actividades que

\footnotetext{
80 Vid. Resolución de 7 de febrero de 2019, del Organismo Autónomo Parques Nacionales, por la que se publica el Acuerdo del Consejo de Ministros de 1 de febrero de 2019.

${ }^{81}$ Conocido también como Banco Le Danois, en referencia al investigador francés que dio a conocer a la comunidad científica este espacio.
} 
se realicen en el espacio protegido. También establece un programa de seguimiento y evaluación.

La gestión y dirección técnica del AMP y de la ZEC de "El Cachucho", le corresponden a la Dirección General de Medio Natural y Política Forestal. Sin perjuicio de las autorizaciones que sean exigibles por aplicación de la legislación sectorial correspondiente, la concesión de las autorizaciones y la emisión de los informes previstos en el Plan de gestión del AMP y de la ZEC corresponderán al Director General de Medio Natural y Política Forestal.

\section{CONCLUSIONES}

La gestión de las áreas marinas protegidas en España constituye un desafío muy relevante por la importancia que tiene el medio marino, en general, y por la significancia y especial trascendencia que tiene en España a efectos ambientales y socioeconómicos.

El concepto de espacio marino protegido engloba los recursos naturales existentes y los ecosistemas que son aprovechados hasta cierto límite dentro de una zona; se habla, así, de "espacios protegidos de uso múltiple", en los que existen limitaciones y prohibiciones, que tratan de ser gestionados racionalmente a través de planes e instrumentos jurídicos específicos en los que conviven diferentes sensibilidades, figuras y estándares de protección.

La zonificación de los espacios naturales marinos exige, a nivel técnico, la adaptación y el respeto a las características ecológicas de los ecosistemas marinos, aplicando principios como los de continuidad ecológica, restauración ambiental, de quien contamina paga, de no regresión ambiental, o de necesidad de llevar a cabo la reparación en la fuente misma.

El objetivo de lograr un buen estado ambiental del medio marino exige una planificación coherente de las actividades que afectan al mismo y queda condicionado, en gran medida, al cumplimiento de los instrumentos de planificación y gestión que disponen las normativas sectoriales. La coordinación entre instrumentos se debe forjar a través del desarrollo de los Planes y programas de medidas de la calidad ambiental (objetivos ambientales) de las aguas continentales y marinas, interdependientes y conectados entre sí. 
La LPNB establece que los entornos marinos a proteger podrán adoptar la categoría de AMPs o protegerse mediante cualquier otra figura de protección de áreas prevista en esta Ley, en cuyo caso, su régimen jurídico será el aplicable a estas otras figuras, sin perjuicio de su inclusión en la RAMPE; respetando sus valores naturales, y estableciendo, al menos, las medidas de conservación necesarias y las limitaciones de explotación de los recursos naturales que procedan.

La RAMPE y las herramientas de inventarización de hábitats integran espacios protegidos en aguas bajo soberanía o jurisdicción española, representativos del patrimonio natural marino; e, independientemente de que su declaración y gestión estén regulados por normas internacionales, comunitarias, estatales o autonómicas, desarrollan una función integrada proporcionando información contrastada, mejorando el conocimiento científico, y permitiendo una gestión interrelacionada entre espacios. Ello permite generar una perspectiva interrelacionada y agregada de las necesidades que presentan estos espacios.

En todo caso, la protección de espacios naturales protegidos (PENP), la Gestión Integrada de Aguas (GIA), la Política Marítima Integrada (PMI), y la Gestión Integrada de Zonas Costeras (GIZC), como políticas que se vienen desarrollando en el seno de la Unión Europea, exigen avanzar en la realización de planteamientos holísticos, insistiendo en la necesidad de alcanzar un marco de protección integral, desarrollando una futura Gestión Integrada de Gestiones Integradas (GIGGII). Esta "integración de políticas integradas" constituye un reto en proceso de convergencia normativa y debe ir fundamentalmente dirigida a estandarizar los objetivos y metodologías para la protección del medio marino a nivel técnico y reglamentario. Dicho lo cual, es justo reconocer que se están sentando las bases para conseguir una integración jurídica efectiva en la protección del medio marino.

Entre los retos y desafíos que se plantean en relación a las áreas marinas protegidas, destacamos la necesidad de:

a) Sistematizar las figuras de protección y las competencias que se proyectan sobre las AMPs de una manera más ordenada. 
b) Favorecer una mayor conectividad natural entre las áreas marinas protegidas por encima de divisiones políticas y administrativas.

c) Depurar el sistema de responsabilidad administrativo en relación a la gestión de la Red de Áreas Marinas Protegidas, limitando la creación de organismos ad hoc y evitando la duplicidad de funciones.

d) Coordinar la actuación Administrativa a nivel técnico y organizacional, favoreciendo la interrelación entre planes y estrategias de regulación y respetando las obligaciones que marcan los Convenios regionales supraestatales.

e) Ampliar la superficie de las AMPs ya protegidas, sobre todo en la zona económica exclusiva y en la plataforma continental; avanzar en el conocimiento científico mediante la delimitación de sistemas de información geográfica y bancos de datos, aumentando la financiación, mejorando de los métodos de intercalibración de datos, etc.

Como reconocen las instituciones comunitarias [COM (2007) 575 final], la Política Marítima Integrada debe poner en liza todos los aspectos de nuestra relación -como seres vivos- con el mar, dentro de un "planteamiento innovador y holístico" orientado a confeccionar un "marco político coherente" que facilite el "desarrollo óptimo y sostenible de todas las actividades". La adaptación de esta política comunitaria, a nivel administrativo, resulta compleja. Por ejemplo, existen veinticinco demarcaciones hidrográficas (cada una de las cuales con sus respectivos planes hidrológicos y problemáticas) por tan sólo cinco demarcaciones marinas, diferentes metodologías, objetivos, etc. Pese a todo, es necesario delimitar la superficie marina por ecorregiones, a modo de grandes demarcaciones ambientales, para procurar un enfoque ecosistémico.

La declaración de las AMPs debe fundarse en la combinación de criterios ecológicos y socioeconómicos que garanticen modelos de sostenibilidad proporcionados y realistas. Uno de los mayores retos consiste en reducir las emisiones contaminantes y en controlar el flujo de residuos que se vierten a nuestros mares y océanos. Se han de intensificar las estrategias para limitar los vertidos contaminantes procedentes de tierra a través de fuentes puntuales de contaminación (como vertidos) o de fuentes de contaminación difusa (nitratos 
empleados en la agricultura, efluentes urbanos e industriales, plaguicidas, hidrocarburos y demás sustancias químicas, etc.), poniendo el acento en el control técnico de los indicadores y descriptores ecológicos, la eliminación de microplásticos, el desarrollo de tecnologías depurativas, un uso y aprovechamiento más sostenible de los entornos costeros...

La protección ambiental debe reconocer el funcionamiento interrelacionado de los ecosistemas tierra-mar, destacando especialmente el papel depurativo que tienen los ecotonos y zonas de transición; ampliando los límites jurisdiccionales; adoptando una visión a largo plazo de sus funciones y objetivos; y, sobre todo, relacionando las necesidades humanas con las capacidades naturales de estos espacios. Por encima de propuestas aisladas que establezcan una gestión autónoma o "más esforzada" de determinados hábitats y zonas se deben conseguir objetivos globales basados en los principios básicos de gestión a nivel de demarcación.

\section{BIBLIOGRAFÍA}

AA.V.: Estudio sobre la implementación de nuevas Áreas Marinas Protegidas en las aguas interiores de la Reserva de la Biosfera de Menorca, así como su gestión y recuperación, I-fish consulting \& market s.I (recuerso electrónico).

AA.V.: EUROPARC-España Anuario 2018 del estado de las áreas protegidas en España EUROPARC-España, Ed. Fundación Fernando González Bernáldez, Madrid, 2019.

AA.V.: Informe "Propuesta de áreas marinas de importancia ecológica: Atlántico Sur y Mediterráneo español', Oceana y Fundación Biodiversidad, 2008.

AA.V.: Un océano de oportunidades. Una política marítima integrada para la Unión Europea, Oficina de publicaciones oficiales de las Comunidades Europeas, Comisión Europea, Luxemburgo, 2007.

AA.V.: UICN, Directrices para las categorías de Manejo de Áreas protegidas, Centro de Parques Nacionales y Áreas Protegidas (CPNAP) - Centro Mundial de Monitoreo de la Conservación (WCMC), Cambridge (Inglaterra), 1995. 
Ariche, M.: "La gobernanza de la biodiversidad marina en las zonas fuera de la jurisdicción nacional: desafíos y perspectivas", en Revista de Estudios Jurídicos de la Univ. de Jaén, núm.16, 2016.

Barreira López, A. (Dir.): Gobernanza para la protección del medio marino en España: Guía Práctica, Instituto Internacional de Derecho y Medio Ambiente (IIDMA), Madrid, 2009.

Biondi, A. et. Al. (Eds.): "Scientific evidence in European Environmental rulemaking”, en Kluwer law international, La Haya (Holanda), 2003.

Caro-Patón, I. y Escartín Escudé, V.: "Aguas: Por una política hidráulica más reflexiva, transparente y participativa”, en López Ramón, F.: Observatorio de Políticas Ambientales, 2015.

Escobar, J.: La contaminación de los ríos y sus efectos en las áreas costeras y el mar, CEPAL: recursos naturales e infraestructuras, Publicación de las Naciones Unidas, Santiago de Chile, 2002.

Fanlo Loras, A.: "Coordinación y prevalencia de la planificación hidrológica en materia de espacios naturales protegidos", en Revista Española de Derecho Administrativo, núm. 182, 2017, pp. 59-80.

Giménez Casalduero, M.: "Las áreas marinas protegidas: nuevas perspectivas a la luz de la ley 42/2007, del patrimonio natural y de la biodiversidad", en Revista catalana de Dret ambiental, Vol. I, núm. 1, 2010, pp. 1-31.

Gjerde, K.M.: "Challenges to protecting the marine environment beyond national jurisdiction", en Int. Journal Mar Coast Law, núm. 27, 2012.

López Menudo, F.: “Las aguas”, en Revista de Administración Pública, núm. 200, 2016.

López Ramón, F.: "Conectividad y corredores ecológicos en la experiencia española", Revista Aragonesa de Administración Pública (ejemplar dedicado a: instrumentos territoriales para la protección de la biodiversidad), núm. 16, 2016, pp. 35-61. 
- "El principio de no regresión en la desclasificación de los espacios naturales protegidos en el Derecho español", en Revista Aranzadi de Derecho Ambiental, núm. 20, 2011.

Martín Mateo, R.: Planificación ambiental oceánica (recurso electrónico).

Navarro Ortega, A.: "La alteración de la dinámica litoral fluvial y marina y su controvertido impacto en el medio: un planteamiento de revisión jurídicoadministrativo de los riesgos inducidos ante el escenario de incertidumbre científica y de cambio climático", en Arana García, E. (Dir.): Riesgos Naturales y Derecho: una perspectiva interdisciplinar, Dykinson, Madrid, 2018, pp. 267-297.

- "La protección integrada del medio marino a través de la directiva marco de aguas y su impacto en el derecho español. Los instrumentos de planificación y gestión", en Arana García, E. y Sanz Larruga, F.J. (Dirs.): La ordenación jurídica del medio marino en España, Civitas, Cizur Menor (Navarra), 2012, pp. 413-455.

- "La gestión integrada del litoral en los Estados Unidos de América y su perspectiva comparada con el régimen jurídico español", en Revista de Administración Pública, núm. 185, 2011, pp. 365-397.

Núñez Lozano, M. C. (Dir.): Hacia una política marítima integrada de la Unión Europea: estudios de política marítima, Madrid, lustel, 2010

Núñez Lozano, M.C. y Zamorano Wisnes, J.: "Ordenación de los espacios marítimos, gestión integrada de zonas costeras y planificación hidrológica", en AA.VV.: Iniciativas en Iberoamérica de interés para la gestión integrada de áreas litorales (Actas del I Congreso Iberoamericano de Gestión Integrada de Áreas Litorales), Cádiz, 2012, pp. 1758 y 1759.

Ortíz García, M., "Las áreas marinas protegidas: avances en su conservación", en López Ramón, F. (Coord.) Observatorio de Políticas Ambientales, Centro de Investigaciones Energéticas, Medioambientales y Técnicas (CIEMAT), 2019, (en prensa).

- "La red de áreas marinas protegidas de España en la protección del medio marino", en Arana García, E. y Sanz Larruga, F.J. (Dirs.): La 
ordenación jurídica del medio marino en España, Civitas, Cizur Menor (Navarra), 2012, pp. 333-380.

- La gestión eficiente de la zona costera. Los parques marinos, Tirant lo Blanch, Valencia, 2003.

- La conservación de la biodiversidad marina: las áreas marinas protegidas, Comares, Granada, 2002.

Pallarés Serrano, A.: "Estudio sobre la prevalencia de los valores ambientales en la interrelación entre los planes hidrológicos de cuenca y los instrumentos de protección de los espacios naturales", en NAVARRO CABALLERO, T.M. (Dir.): Desafíos del Derecho de aguas. Variables jurídicas, económicas, ambientales y de Derecho comparado, Aranzadi, Cizur Menor, 2016, págs. 237-251.

Pascual Fernández, J.J. y De La Cruz Modino, R.: "Los espacios marinos protegidos en España: ¿nuevas formas institucionales para las estrategias de apropiación?", en Beltrán, O, Pascual, J.J. y Vaccaro, I. (Coord.): Patrimonialización de la naturaleza. El marco social de las políticas ambientales, pp. 199-221 (recurso electrónico).

PNUMA: Fronteras 2017. Nuevos temas de interés ambiental, Programa de las Naciones Unidas para el Medio Ambiente, Nairobi (Kenia), 2017.

Ricard, P.: "Les aires marines protégées en haute mer et la difficile conciliation entre droit de la mer et droit de l'environnment", en Chaumette, P. (Coord.): Transforming the ocean law by requirement of the marine environment conservation, Marcial Pons, Madrid, 2019, pp. 249-269.

Sanz Larruga, Francisco Javier: "La nueva ordenación del espacio marítimo: análisis del Real Decreto 363/2017, de 8 de abril”, en Práctica urbanística: Revista mensual de urbanismo, núm. 150, 2018.

- "La planificación ambiental se vuelca en el mar: la nueva ordenación del espacio marítimo", en Revista Aranzadi de Derecho Ambiental, núm. 37, 2017.

Suárez de Vivero, J.L. y Rodríguez Mateos, J.C.: "España en el contexto europeo (La Ley de protección del medio marino y la planificación espacial marina)", 
Revista Ambienta, núm. 94, Ministerio de Medio Ambiente y Medio Rural y Marino, 2011.

Valencia Martín, G.: ¿De quién es el mar?: La distribución de competencias entre el estado y las comunidades autónomas en materia de protección del medio marino, en SOSA WAGNER (Coord.): El derecho administrativo en el umbral del siglo XXI: homenaje al profesor Dr. D. Ramón Martín Mateo, Tirant lo Blanch, 2000.

Valladares, F., Gil, P. y Forner, A. (coord.): Bases científico-técnicas para la Estrategia estatal de infraestructura verde y de la conectividad y restauración ecológicas. Ministerio de Agricultura y Pesca, Alimentación y Medio Ambiente. Madrid, 2017, 357 pp.

Zamorano Weiss, J.: "La ordenación de los espacios marinos en la Unión Europea”, Revista Aranzadi de Derecho ambiental, núm. 39, 2018. 